WSRC-TR-2004-00370

Revision 0

\title{
Spectrometric Analysis for Pulse Jet Mixer Testing
}

\section{Kristine Eland Zeigler}

\author{
Unclassified \\ Does Not Contain Unclassified Controlled Nuclear Information (UCNI)
}

July 12,2004

Westinghouse Savannah River Company

Savannah River Site

Aiken, SC 29808

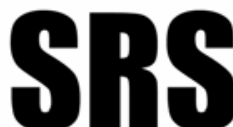

savannah river site 
This document was prepared in conjunction with work accomplished under Contract No. DE-AC09-96SR18500 with the U. S. Department of Energy.

\section{DISCLAIMER}

This report was prepared as an account of work sponsored by an agency of the United States Government. Neither the United States Government nor any agency thereof, nor any of their employees, makes any warranty, express or implied, or assumes any legal liability or responsibility for the accuracy, completeness, or usefulness of any information, apparatus, product or process disclosed, or represents that its use would not infringe privately owned rights. Reference herein to any specific commercial product, process or service by trade name, trademark, manufacturer, or otherwise does not necessarily constitute or imply its endorsement, recommendation, or favoring by the United States Government or any agency thereof. The views and opinions of authors expressed herein do not necessarily state or reflect those of the United States Government or any agency thereof.

This report has been reproduced directly from the best available copy.

Available for sale to the public, in paper, from: U.S. Department of Commerce, National Technical Information Service, 5285 Port Royal Road, Springfield, VA 22161, phone: (800) 553-6847, fax: (703) 605-6900

email: orders@ntis.fedworld.gov

online ordering: http://www.ntis.gov/help/index.asp

Available electronically at http://www.osti.gov/bridge

Available for a processing fee to U.S. Department of Energy and its contractors, in paper, from: U.S. Department of Energy, Office of Scientific and Technical Information, P.O. Box 62, Oak Ridge, TN 37831-0062,

phone: (865)576-8401,

fax: (865)576-5728

email: $\underline{\text { reports@ adonis.osti.gov }}$ 
This page was intentionally left blank 
WSRC-TR-2004-00370, Rev. 0 July 12, 2004

Page 4 of 45

\section{TABLE OF CONTENTS}

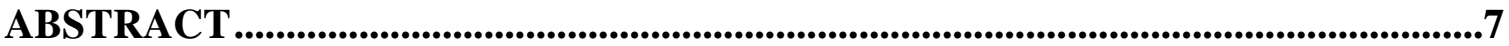

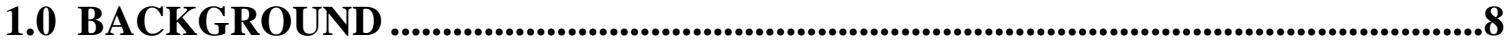

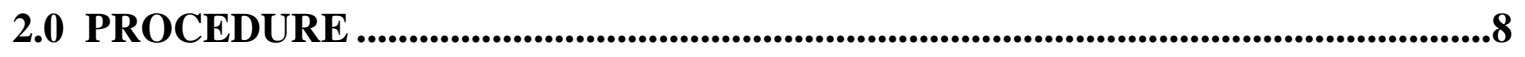

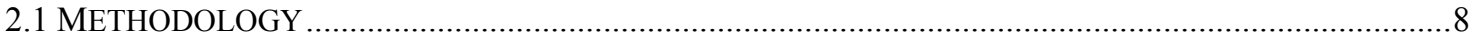

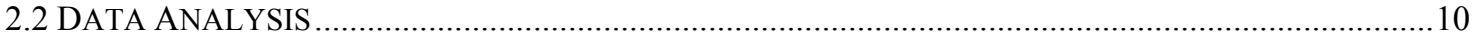

3.0 RESULTS .......................................................................................................................11

3.1 TEST 1, 10 PA FIGURE 1, TABLE 1 1/14/04 ....................... ERROR! BOOKMARK NOT DEFINED.

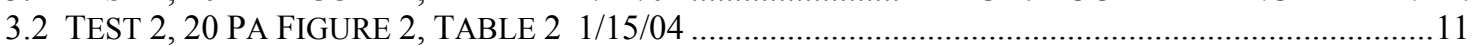

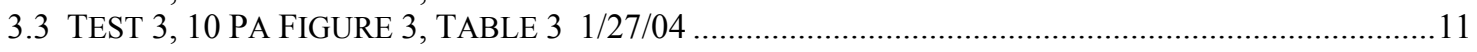

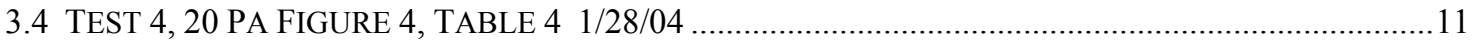

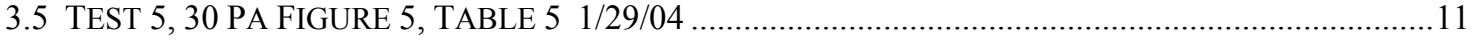

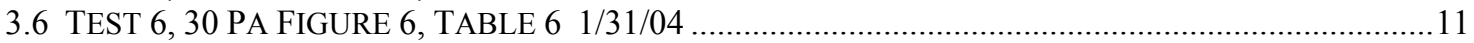

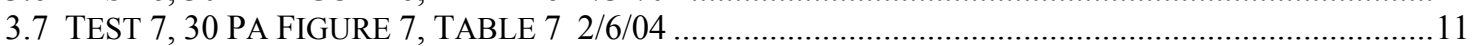

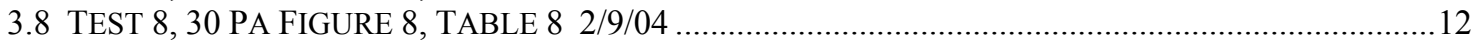

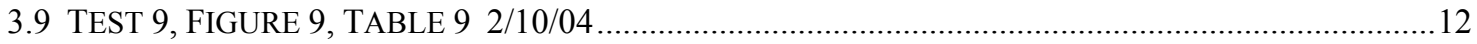

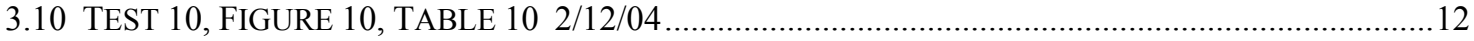

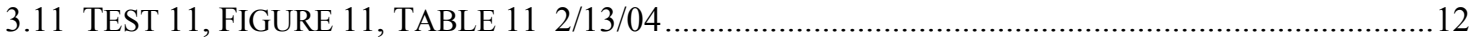

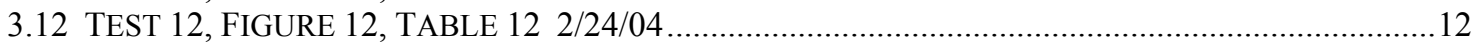

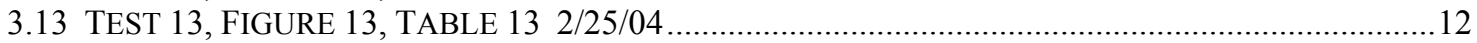

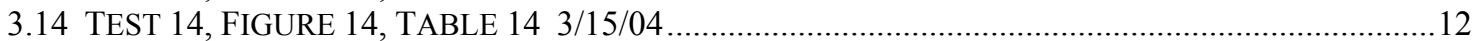

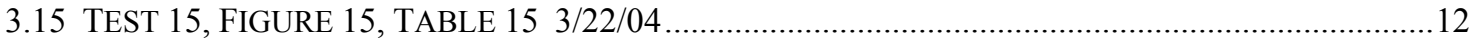

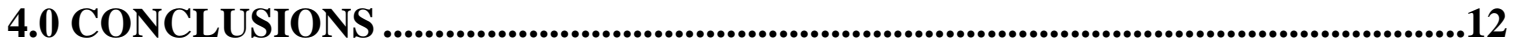

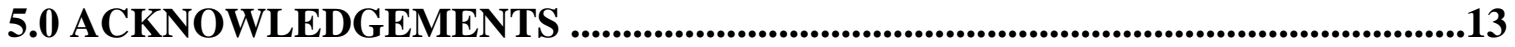

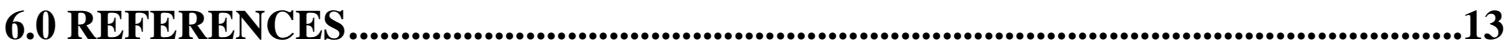


WSRC-TR-2004-00370, Rev. 0 July 12,2004

Page 5 of 45

\section{LIST OF FIGURES}

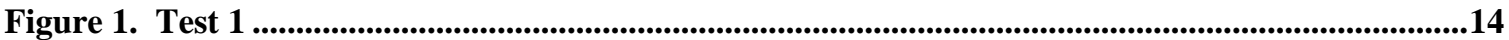

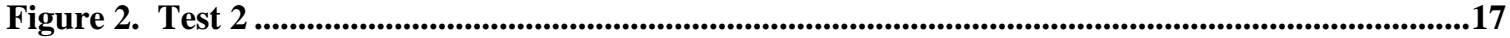

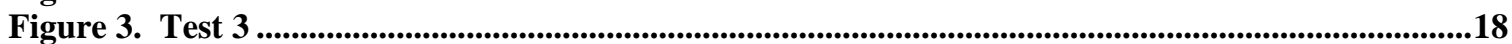

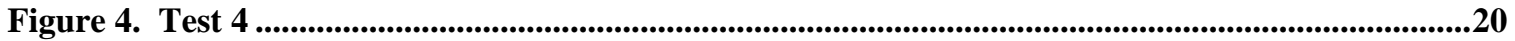

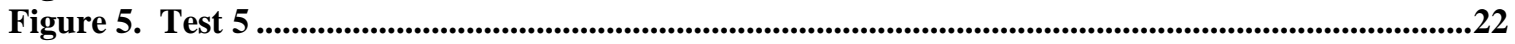

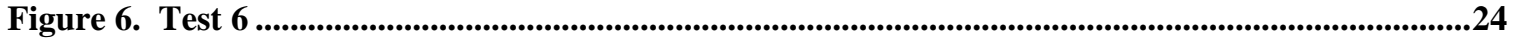

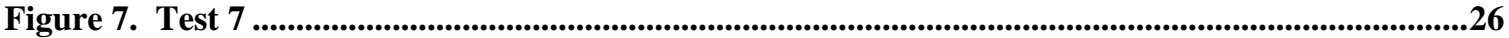

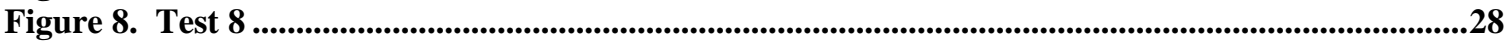

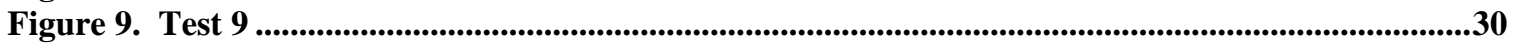

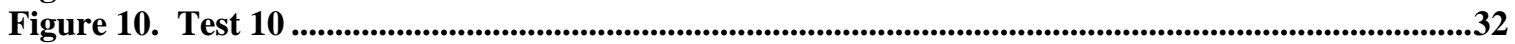

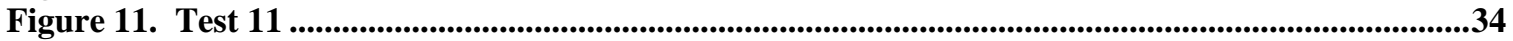

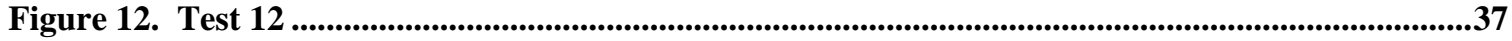

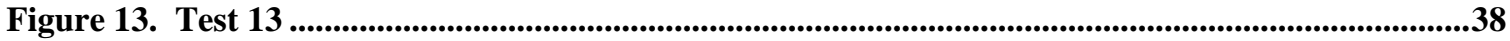

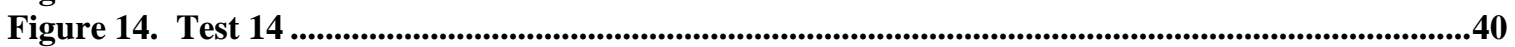

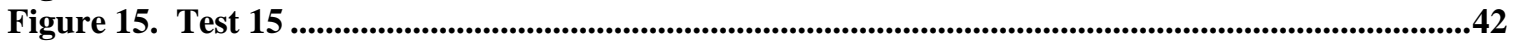

\section{LIST OF TABLES}

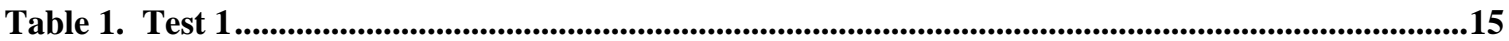

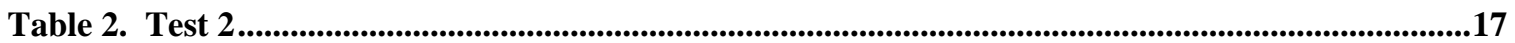

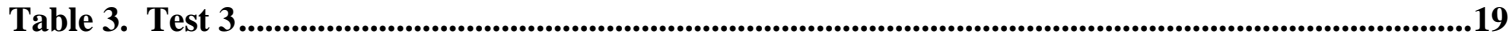

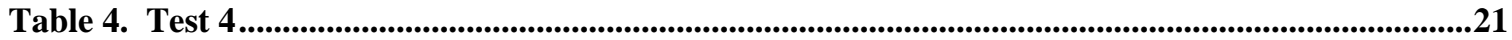

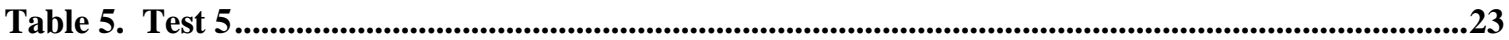

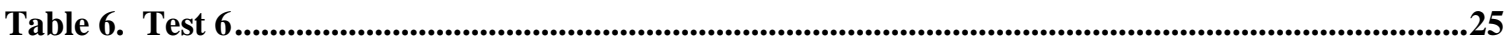

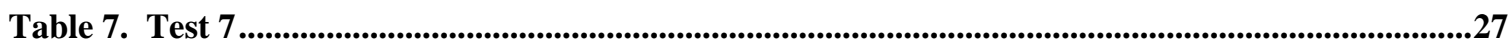

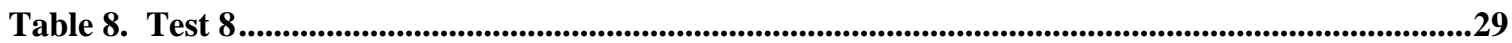

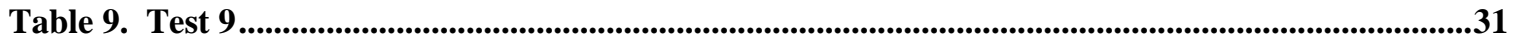

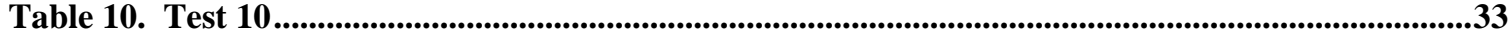

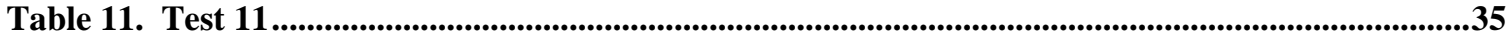

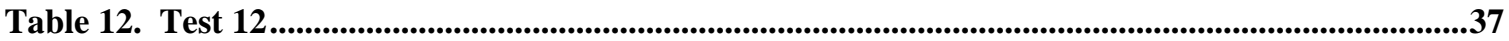

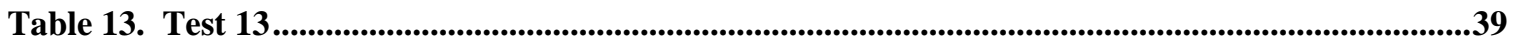

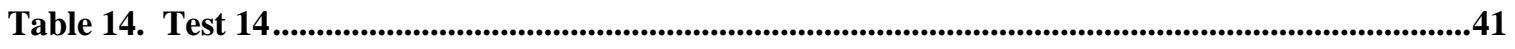

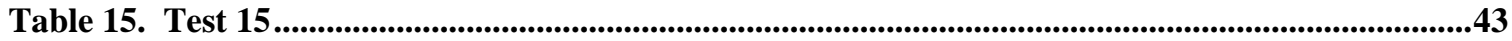

\section{APPENDIX}

Appendix 1. Test 8-Dilution factor curves and percent mixed calculation.............................44 


\section{LIST OF ACRONYMS and ABBREVIATIONS}

$\begin{array}{ll}\text { abs } & \text { absorbance } \\ \text { ADS } & \text { Analytical Development Section } \\ \text { CRV } & \text { Concentrate Receipt Vessel } \\ \text { DOE } & \text { Department of Energy } \\ \text { EDL } & \text { Engineering Development Lab } \\ \text { g } & \text { grams } \\ \text { nm } & \text { nanometer } \\ \text { PJM } & \text { pulse jet mixer } \\ \text { PNNL } & \text { Pacific Northwest National Laboratory } \\ \text { RPP-WTP } & \text { Hanford River Protect Program- Waste Treatment Program } \\ \text { SRS } & \text { Savannah River Site (Aiken, SC) } \\ \text { UV-Vis } & \text { ultraviolet-visible }\end{array}$


WSRC-TR-2004-00370, Rev. 0

July 12, 2004

Page 7 of 45

\begin{abstract}
The Analytical Development Section (ADS) was tasked with providing support for a Hanford River Protection Program-Waste Treatment Program (RPP-WTP) project test involving absorption analysis for non-Newtonian pulse jet mixer testing for small scale (PJM) and prototype (CRV) tanks with sparging. Tanks filled with clay were mixed with various amounts of powdered dye as a tracer. The objective of the entire project was to determine the best mixing protocol (nozzle velocity, number of spargers used, total air flow, etc.) by determining the percent mixed volume through the use of an ultravioletvisible (UV-Vis) spectrometer. The dye concentration within the sample could be correlated to the volume fraction mixed in the tank. Samples were received in vials, a series of dilutions were generated from the clay, allowed to equilibrate, then centrifuged and siphoned for the supernate liquid to analyze by absorption spectroscopy. Equilibration of the samples and thorough mixing of the samples were a continuous issue with dilution curves being difficult to obtain. Despite these technical issues, useful data was obtained for evaluation of various mix conditions.
\end{abstract}


WSRC-TR-2004-00370, Rev. 0

July 12, 2004

Page 8 of 45

\subsection{BACKGROUND}

During pulse jet mixer (PJM) testing of Hanford's Concentrate Receipt Vessel (CRV), it is difficult to visually detect the mixed volume within the tank. A spectrophotometric method was developed where a dye is injected into the mixed zone and at different operating conditions of the PJM, the dye concentration can be correlated to the volume fraction mixed ${ }^{1}$. For correct analysis, it is essential to collect and analyze several samples from the tank cavern during testing under each PJM operating condition.

The Analytical Development Section (ADS) was asked by Engineering Development Laboratory (EDL) personnel to aid in the analysis of dyed clay samples in support of this River Protection Program- Waste Treatment Program (RPP-WTP) project. These samples were originally being sent to an outside laboratory for analysis however, turn around time was insufficient and the amount of tests that were planned would generate numerous samples. ADS was asked to analyze the samples following Procedure TI-RPPWTP-336, Dye Injection, Sampling, and Spectrometric Analysis for Non-Newtonian PJM Testing for Small Scale (4PJM) and Prototype (UFP \& LS) Tanks with Sparging. Injection of the dye and sample collection was handled by EDL personnel while the analysis of the samples using an ultraviolet-visible (UV-Vis) spectrometer was performed by ADS.

More specific details of this testing, including the information on the mixing and various parameters can be found in a different report. This document only contains the actual spectrometric analysis information and the subsequent data.

\subsection{Procedure}

\subsection{Methodology}

The procedure followed for this testing, TI-RPP-WTP-336, was developed by Pacific Northwest National Laboratory (PNNL) personnel. Samples were analyzed for their absorbance and each run condition was compared for any change in the mixing. The clay was considered mixed if there was not a significant change in the absorbance reading. To determine the percent mixed volume, a series of dilutions were made for each run (from one position in the tank and the last timed sample, 5).

Each run condition (labeled A, B, C, or D along with the test number in front of the letter) had a corresponding series of dilutions, except for the final run. For each test, there were 4 different sites within the mixing tank from which samples were taken (labeled 1, 2, 3, or 4). Finally, the samples were taken every 10 minutes, for a total of 5 times (labeled 1, 2, 3, 4, or 5 with time 5 being the last sample taken). An example of the labeling is 2-4C-3, which meant this sample was from position 2 in test 4 for PJM run condition $\mathrm{C}$, as the $4^{\text {th }}$ sample taken. Also, an initial baseline sample was taken before a test began. This baseline was used for the dilutions and an initial reading. This baseline clay sometimes contained dye (it was clay used from the previous testing). A final sample was also taken, after the vessel was completely homogenized, usually about 30 minutes after the final time, 5.

There were many technical issues encountered at the onset of these analyses and personnel at PNNL were contacted for further instructions ${ }^{2}$. After correspondence, it was 
WSRC-TR-2004-00370, Rev. 0

July 12, 2004

Page 9 of 45

discovered that small details had been omitted from the procedure being followed. Examples of these issues included the amount of material needed for dilutions, sample mixing concerns including vortexing, and equilibration. After numerous conversations, the following, more detailed steps were generated for use in handling the samples along with additional important information.

1. Seven scintillation vials will be labeled with sample number, tared and recorded. The use of plastic scintillation vials (Fisherbrand $20 \mathrm{~mL}$ Plastic Scintillation Vials with PP cap) makes for easier removal of all of the clay from the vial.

2. Shake sample vigorously. Using a plastic transfer pipet, place clay material from the previous run into tared and labeled vials (total volume of clay after additions should be at least $10 \mathrm{~g})$. Record weight.

The dilution series must be made immediately after the samples are collected so that ideally, the $100 \%$ mixed sample and dilution series would be in contact with the baseline clay for the same amount of time. If the dilution series is not made immediately after the samples are collected, the diluted samples need to equilibrate for 48 hours before centrifuging.

3. Shake baseline clay vigorously. Calculate the appropriate amount of baseline clay to be added to the sample clay to produce dilution factors of $1.05,1.10,1.20$, 1.40, 1.60, 1.80 and 2.00 grams. Dilution factor is calculated as the ratio of the final mass to the original sample.

With the total amount of clay in the vial being 10 grams, one can calculate the amount of initial clay needed to total $10 \mathrm{~g}$ for each of the dilution series. It is actually better to use a larger amount of clay to make the dilutions, however, in the beginning of testing we were limited to only a small vial of clay $(<20 \mathrm{~mL})$ that needed to be diluted among 8 vials. (Very early tests only used about a total of 3 grams in the dilution series. This is why there was such a problem with the linearity of the dilution curves. Ultimately the dilution series was ceased because of the linearity problem with the curves. Therefore, only a comparison of each run, not actual percent mixed, was determined, as per EDL personnel.)

4. With a plastic transfer pipet, add the appropriate amount of baseline clay to the clay in vial.

The approximate amount of baseline clay needed is calculated for a total mass of $10 \mathrm{~g}$. A spreadsheet was used with the measured weights to get the exact dilution factors.

5. Cap the vial, shake vigorously to mix and let sit for at least 24 hours.

The clay needed to sit for 24 hours to allow for equilibration.

6. Shake diluted sample vial. Transfer the diluted clay with a transfer pipet to centrifuge vial. Fill about $1 / 3$ to $1 / 2$ full. Cap the vial. Also transfer other samples not used in dilution series.

(Kimble Glass 10mL Conical Bottom Glass Centrifuge Tubes with phenolic cap) 
WSRC-TR-2004-00370, Rev. 0

July 12, 2004

Page 10 of 45

7. Vortex the dilution series samples for $\mathbf{3}$ minutes to ensure a thorough mix.

The vortexing can either be performed while the sample is in the scintillation vial, or after it is transferred to the centrifuge vial.

8. Centrifuge the sample for 50-60 minutes. If the liquid is not clear of particulates, centrifuge longer.

When looking at the supernate liquid, one can identify a clear solution versus one with particulates floating around which may interfere with the UV-Vis absorption reading.

9. Transfer supernate liquid on top of compacted solid with a diposable glass pipet to a plastic cuvette.

(Fisherbrand Semi UV $1.5 \mathrm{~mL}$ Cuvette with cap)

10. Zero instrument using deionized water. Place cuvette in UV-Vis sample holder.

11. Analyze absorbance at $\sim 630 \mathrm{~nm}$. Record absorbance at $630 \mathrm{~nm}$ and at a wavelength outside the absorbance range of the dye $(\sim 730 \mathrm{~nm})$. Subtract the two for the absorbance reading.

12. If the absorbance is greater than 1.5, dilute the supernate with deionized water. Record the amount of supernate and water used in the dilution.

The spectrometer (J\&M Tidas Spectrometer with Ocean Optics Inc. CUV Sample Holder) software (Tidas Spectralys 2.0 Software) was set to average 30 spectra with a 10 ms exposure. The light source (Ocean Optics Inc. LS-1 tungsten halogen light source) was monitored every 8 samples for drift.

Appropriate quality assurance controls were taken to ensure proper measurements. The balance (Denver Instruments M-310 Balance, MT\&E no. AD-0075) was checked and calibrated when needed, and recorded in the MT\&E \#AD-0075 control log. The spectrometer was referenced with deionized water, after the instrument had equilibrated for 30 minutes, every $8^{\text {th }}$ sample and after every test and a new dark current spectra was taken at this time too. The instrument was monitored for any drift in the light source or fiber alignment issues during those times also.

\subsection{Data Analysis}

The absorbance versus dilution factor is plotted for set A of the dilution samples. On this plot, the undiluted sample from set A is also plotted as dilution factor 1.0 (it should be the highest absorbance reading). Also on this plot, from its absorbance reading, place the original sample from set B. From this point, interpolate the dilution factor in the PJM vessel. Next, plot the dilution series from set B along with the undiluted set B sample. On this plot, place the absorbance for the undiluted set $\mathrm{C}$ sample and interpolate the dilution factor. Do this for set $\mathrm{C}$ and set $\mathrm{D}$. The final homogenized sample absorbance reading will be plotted on the curve from set $\mathrm{D}$ and the dilution factor will be interpolated. This method minimizes problems associated with the mass balance dye method by re-baselining the dye concentrations at each run condition. To calculate volume mixed in each run, remember that the dilution factor is equal to the final mass divided by the initial sample mass. For Run D, the final homogenized sample's 
WSRC-TR-2004-00370, Rev. 0

July 12, 2004

Page 11 of 45

interpolated dilution factor is equal to $100 \%$ divided by the unknown initial sample mass. This will be the percent mixed for run $\mathrm{D}$. Next, the undiluted sample from run $\mathrm{D}$ that was plotted on the run $\mathrm{C}$ curve is the dilution factor and that is equal to the percentage calculated previously (percent mixed for run D) divided by the unknown initial sample mass. This percent mixed will be used to calculate for the unknown initial sample mass for the $\mathrm{B}$ run and then this percent mixed will be used to calculate the mixed percent for run A. An example of this can be found in Appendix A.

For all other samples collected, a simple bar graph indicates the change of mixing for the various times and sampling points. Standard deviation was calculated for some samples and is indicated by error bars on the graphs. (In the beginning of testing, multiple samples were not run for each test because there were so many samples, results were needed and the focus was on understanding the technical issues with the dilution sets. As the tests continued however, multiple samples were taken from a vial to calculate for standard deviation, $3 \sigma$.)

\subsection{RESULTS}

On each of the graphs, the absorbance versus time, is plotted for each run condition for a particular position $(1,2,3$, or 4$)$. The bar graphs begin with the starting clay (the initial baseline absorbance, I), show the absorbance over the various times collected (1-5) and end with the final absorbance (F) of the final homogenized clay for that particular test. The results given here can be found in WSRC-NB-2004-00012 $2^{3}$. The dilution curves are not contained in this report, but can be found in the Notebook as well.

\subsection{Test 1, 10 Pa Figure 1, Table 1 1/14/04}

Test 1 only contains information for the first time collected and the fifth time collected.

\subsection{Test 2, 20 Pa Figure 2, Table 2 1/15/04}

Test 2 contains information collected over the entire test period. The very low initial (I) absorbance indicates the use of undyed clay when staring the test.

\subsection{Test 3, 10 Pa Figure 3, Table 3 1/27/04}

Test 3 contains only information for the first and fifth times collected.

\subsection{Test 4, 20 Pa Figure 4, Table 4 1/28/04}

Test 4 contains only information for the first and fifth times collected.

\subsection{Test 5, 30 Pa Figure 5, Table 5 1/29/04}

Test 5 contains information for the entire time collected for the first position and only the first and fifth times collected for the remaining positions. The initial absorbance (I) reading indicates the use of fresh undyed clay.

\subsection{Test 6, 30 Pa Figure 6, Table 6 1/31/04}

Test 6 data only contains the information for the fifth reading. Problems were still being encountered with the dilution curves and with the samples being thoroughly mixed. These issues were being resolved and only the last collection and final mixed clay absorbances were requested.

\subsection{Test 7, 30 Pa Figure 7, Table 7 2/6/04}


WSRC-TR-2004-00370, Rev. 0

July 12,2004

Page 12 of 45

Test 7 data contains the first, third and fifth collection times. Again, undyed clay was used at the onset of this test.

\subsection{Test 8, 30 Pa Figure 8, Table 8 2/9/04}

Test 8 data contains information collected over the entire test period. For this test however, only three different conditions were used (A, B, and C).

\subsection{Test 9, Figure 9, Table 9 2/10/04}

Test 9 data contains information collected over the entire test period. For this test only three different conditions were used (A, B, and C).

\subsection{Test 10, Figure 10, Table 10 2/12/04}

Test 10 data contains information collected over the entire test period. For this test only three different conditions were used (A, B, and C).

\subsection{Test 11, Figure 11, Table 11 2/13/04}

Test 11 data contains information collected over the entire test period. For this test only three different conditions were used (A, B, and C).

\subsection{Test 12, Figure 12, Table 12 2/24/04}

Test 12 contains data collected for only three times and following one condition (A) only. Times 2, 3 and final are statistically the same absorbance reading.

\subsection{Test 13, Figure 13, Table 13 2/25/04}

Test 13 contains data collected for only three times and following one condition (A) only. Times 2, 3 and final are statistically the same absorbance reading.

\subsection{Test 14, Figure 14, Table 14 3/15/04}

Test 14 contains data collected for only three times and following one condition (A) only. Times 2, 3 and final are statistically the same absorbance reading.

\subsection{Test 15, Figure 15, Table 15 3/22/04}

Test 15 contains data collected for only three times and following one condition (A) only. Times 2, 3 and final are statistically the same absorbance reading.

\subsection{CONCLUSIONS}

This document contains all the absorption data requested for the pulse jet mixing tests and has been used in data analysis by EDL personnel. Many technical issues were encountered with the original procedure that was given for this work. After many discussions with EDL and PNNL personnel, a more detailed procedure was produced. However, the dilution curves were still a problem with results varying and the typical trend not being followed.

One of the technical issues discussed was the introduction of dye to the tank. ADS personnel believed that one sample homogenization was a major concern. Upon opening the sample vials, swirls of blue dye could be viewed which was an indication that the dye was not mixed properly before being distributed to the tank. We believe if the dye was introduced as a solution, that is completely dissolved into water before introduction, the blending of the tank would have been more effiecient. EDL personnel indicated that due 
to mass balance issues, nothing more could be introduced into the tank. One possible solution discussed was to centrifuge the initial tank clay and siphon off the liquid to mix with the dye. This however did not work as planned because not enough liquid could by siphoned off to mix with the large amount of dye. After this attempt, it was decided to take a certain amount of the initial clay and mix it in a blender with the dye. This did not completely solve the mixing issue but did help.

This report contains the information given to EDL personnel for their data interpretation. Although the intention of this work was to determine the percentage mixed within a tank under various conditions, because of the technical issues encountered with the original procedure, it does not report the percent mixed, but only addresses absorption data for all the samples. From this, an improved, more detailed procedure was developed through discussions with PNNL and EDL personnel. Useful data from the sample absorption graphs were obtained for analysis.

\subsection{ACKNOWLEDGEMENTS}

The author would like to thank April Ward, Beverly Burch, Angie Bowman, Elaine Pearson, Neta Rutland, Annie Still, Pam Waller, Adrienne Williams and Shirley Brunson-Brown for their help with the analysis.

\subsection{REFERENCES}

1. Procedure TI-RPP-WTP-336, Dye Injection, Sampling, and Spectrometric Analysis for Non-Newtonian PJM Testing for Small Scale (4PJM) and Prototype (UFP \& LS) Tanks with Sparging

2. Personal correspondence with Adam Poloski, PNNL Scientist, 1/15/04, 1/28/04, 2/2/04, 2/6/04, 2/12/04.

3. Zeigler, K. Clay Analysis, WSRC-NB-2004-00012. 
WSRC-TR-2004-00370, Rev. 0

July 12, 2004

Page 14 of 45
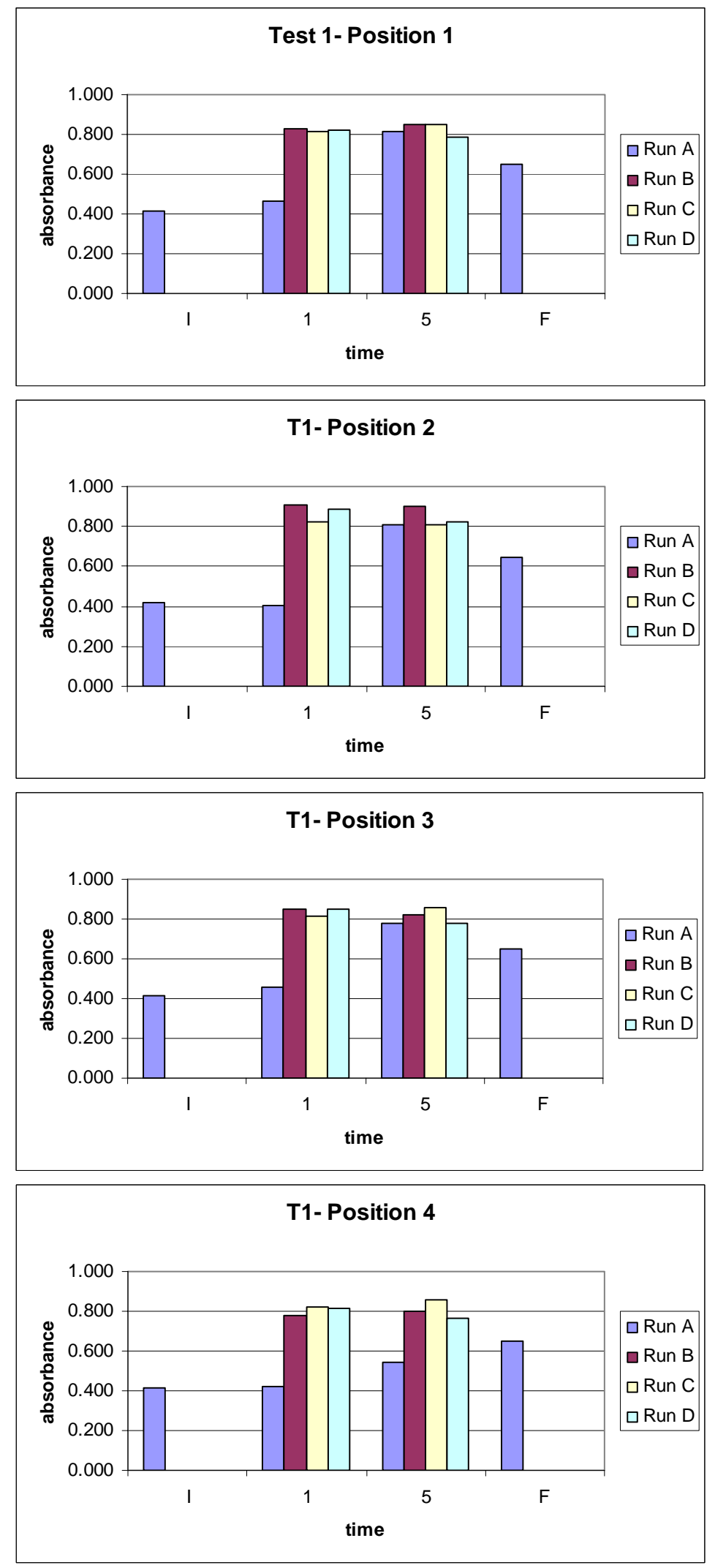

Figure 1. Test 1

Test 1 
WSRC-TR-2004-00370, Rev. 0 July 12, 2004

Page 15 of 45

\begin{tabular}{|c|c|c|c|c|c|c|c|}
\hline $\begin{array}{c}\text { Sample } \\
\text { DI }\end{array}$ & $\begin{array}{c}\text { Abs } \\
0.415\end{array}$ & Sample & Abs & Sample & Abs & Sample & Abs \\
\hline $1 \mathrm{~A} 1$ & 0.461 & 1B1 & 0.831 & $1 \mathrm{C} 1$ & 0.812 & 1D1 & 0.820 \\
\hline $1 \mathrm{~A} 5$ & 0.812 & 1B5 & 0.849 & $1 C 5$ & 0.853 & 1D5 & 0.787 \\
\hline DF & 0.648 & & & & & & \\
\hline $\mathrm{DI}$ & 0.415 & & & & & & \\
\hline $2 \mathrm{~A} 1$ & 0.405 & 2B1 & 0.905 & $2 \mathrm{C} 1$ & 0.820 & 2D1 & 0.890 \\
\hline $2 \mathrm{~A} 5$ & 0.809 & 2B5 & 0.904 & $2 \mathrm{C5}$ & 0.812 & 2D5 & 0.822 \\
\hline DF & 0.648 & & & & & & \\
\hline DI & 0.415 & & & & & & \\
\hline $3 A 1$ & 0.459 & 3B1 & 0.848 & $3 \mathrm{C1}$ & 0.817 & 3D1 & 0.851 \\
\hline $3 A 5$ & 0.777 & 3B5 & 0.821 & $3 C 5$ & 0.856 & 3D5 & 0.776 \\
\hline DF & 0.648 & & & & & & \\
\hline DI & 0.415 & & & & & & \\
\hline $4 \mathrm{~A} 1$ & 0.419 & 4B1 & 0.781 & $4 C 1$ & 0.824 & 4D1 & 0.816 \\
\hline $4 A 5$ & 0.546 & 4B5 & 0.801 & $4 C 5$ & 0.859 & 4D5 & 0.765 \\
\hline DF & 0.648 & & & & & & \\
\hline
\end{tabular}

Table 1. Test 1 
WSRC-TR-2004-00370, Rev. 0

July 12, 2004

Page 16 of 45

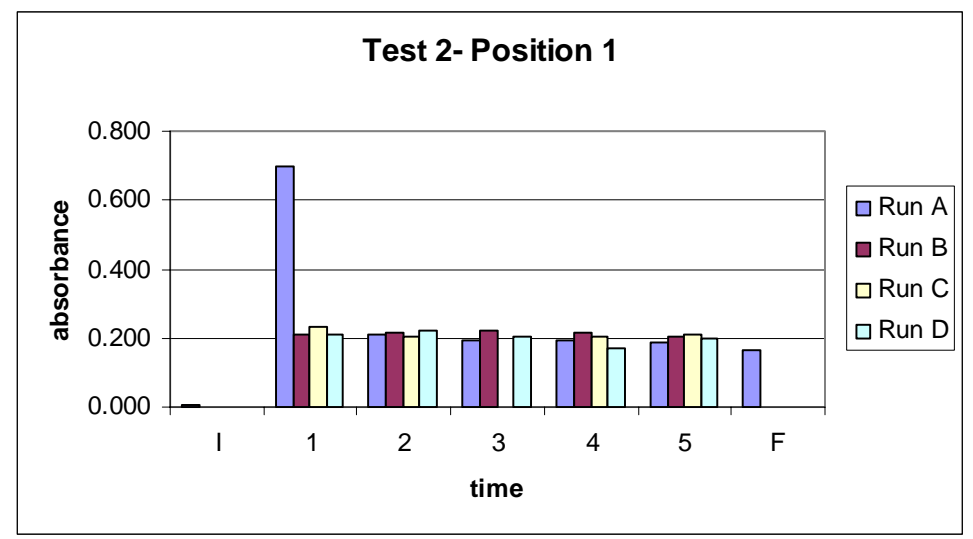

T2- Position 2

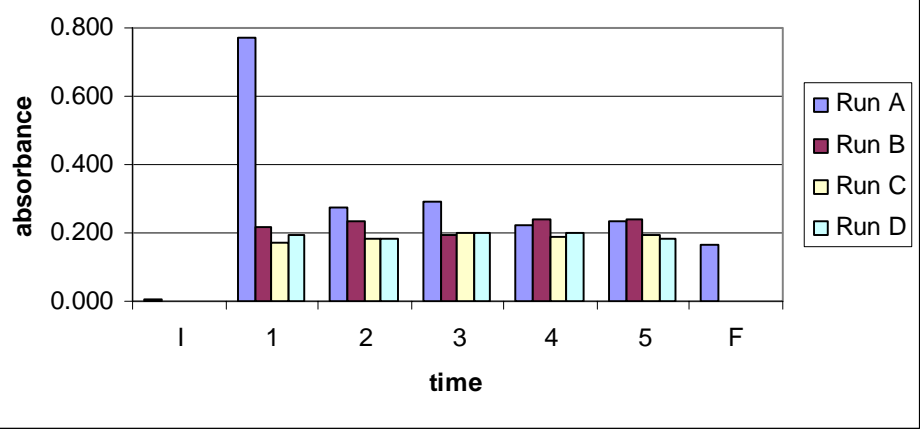

T2- Position 3

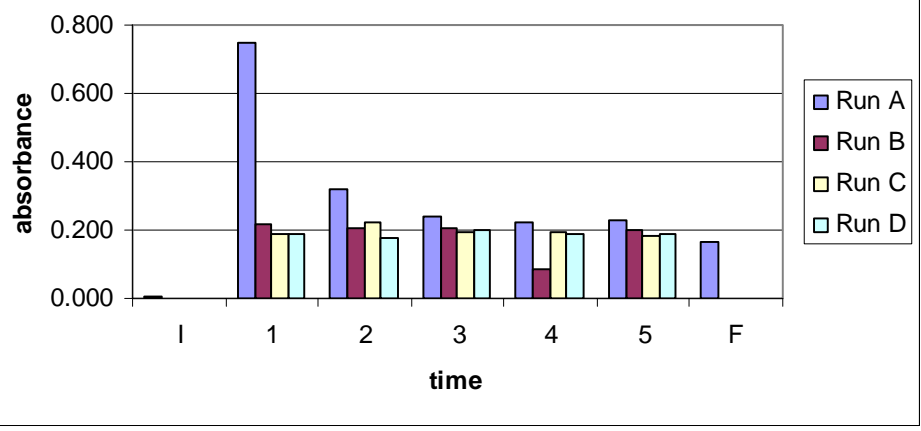

T2- Position 4

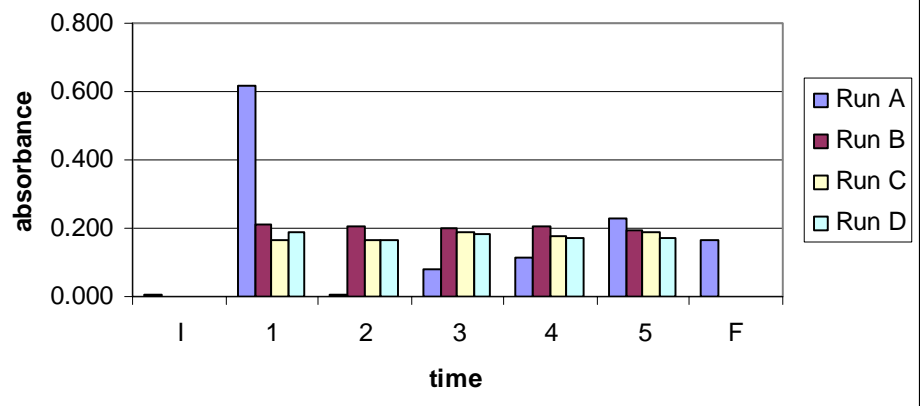


WSRC-TR-2004-00370, Rev. 0 July 12, 2004

Page 17 of 45

Figure 2. Test 2

\begin{tabular}{|c|c|c|c|c|c|c|c|}
\hline \multicolumn{8}{|c|}{ Test 2-20Pa } \\
\hline Sample & Abs & Samp & Abs & Samp & Abs & Samp & Abs \\
\hline 12A1 & 0.697 & 12B1 & 0.209 & $12 \mathrm{C} 1$ & 0.231 & 12D1 & 0.208 \\
\hline $12 \mathrm{~A} 2$ & 0.211 & 12B2 & 0.217 & $12 \mathrm{C} 2$ & 0.206 & 12D2 & 0.223 \\
\hline $12 \mathrm{~A} 3$ & 0.193 & $12 \mathrm{~B} 3$ & 0.220 & & & $12 \mathrm{D} 3$ & 0.202 \\
\hline $12 \mathrm{~A} 4$ & 0.193 & 12B4 & 0.215 & $12 \mathrm{C} 4$ & 0.203 & 12D4 & 0.168 \\
\hline $12 \mathrm{~A} 5$ & 0.187 & 12B5 & 0.204 & $12 \mathrm{C5}$ & 0.208 & 12D5 & 0.199 \\
\hline DF & 0.167 & & & & & & \\
\hline DI & 0.005 & & & & & & \\
\hline $22 \mathrm{~A} 1$ & 0.770 & 22B1 & 0.216 & $22 \mathrm{C1}$ & 0.172 & 22D1 & 0.195 \\
\hline $22 \mathrm{~A} 2$ & 0.276 & 22B2 & 0.236 & $22 \mathrm{C} 2$ & 0.182 & 22D2 & 0.180 \\
\hline $22 \mathrm{~A} 3$ & 0.290 & 22B3 & 0.196 & $22 \mathrm{C} 3$ & 0.201 & 22D3 & 0.201 \\
\hline $22 \mathrm{~A} 4$ & 0.225 & 22B4 & 0.242 & $22 \mathrm{C} 4$ & 0.187 & 22D4 & 0.202 \\
\hline $22 \mathrm{~A} 5$ & 0.236 & 22B5 & 0.242 & $22 \mathrm{C5}$ & 0.192 & 22D5 & 0.182 \\
\hline DF & 0.167 & & & & & & \\
\hline DI & 0.005 & & & & & & \\
\hline $32 \mathrm{~A} 1$ & 0.748 & 32B1 & 0.217 & $32 \mathrm{C1}$ & 0.186 & 32D1 & 0.188 \\
\hline $32 \mathrm{~A} 2$ & 0.317 & 32B2 & 0.208 & $32 \mathrm{C} 2$ & 0.225 & 32D2 & 0.177 \\
\hline $32 \mathrm{~A} 3$ & 0.242 & $32 \mathrm{~B} 3$ & 0.207 & $32 \mathrm{C3}$ & 0.194 & $32 \mathrm{D} 3$ & 0.199 \\
\hline $32 \mathrm{~A} 4$ & 0.225 & 32B4 & 0.088 & $32 \mathrm{C} 4$ & 0.193 & $32 \mathrm{D} 4$ & 0.191 \\
\hline $32 \mathrm{~A} 5$ & 0.227 & 32B5 & 0.197 & $32 C 5$ & 0.181 & 32D5 & 0.190 \\
\hline DF & 0.167 & & & & & & \\
\hline DI & 0.005 & & & & & & \\
\hline $42 \mathrm{~A} 1$ & 0.616 & 42B1 & 0.212 & $42 \mathrm{C} 1$ & 0.168 & 42D1 & 0.190 \\
\hline $42 \mathrm{~A} 2$ & 0.004 & 42B2 & 0.203 & $42 \mathrm{C} 2$ & 0.165 & 42D2 & 0.167 \\
\hline $42 \mathrm{~A} 3$ & 0.080 & 42B3 & 0.202 & $42 \mathrm{C} 3$ & 0.186 & 42D3 & 0.182 \\
\hline $42 \mathrm{~A} 4$ & 0.112 & 42B4 & 0.204 & $42 \mathrm{C} 4$ & 0.178 & 42D4 & 0.169 \\
\hline $42 \mathrm{~A} 5$ & 0.226 & 42B5 & 0.193 & $42 C 5$ & 0.187 & 42D5 & 0.169 \\
\hline DF & 0.167 & & & & & & \\
\hline
\end{tabular}

Table 2. Test 2 
WSRC-TR-2004-00370, Rev. 0

July 12, 2004

Page 18 of 45
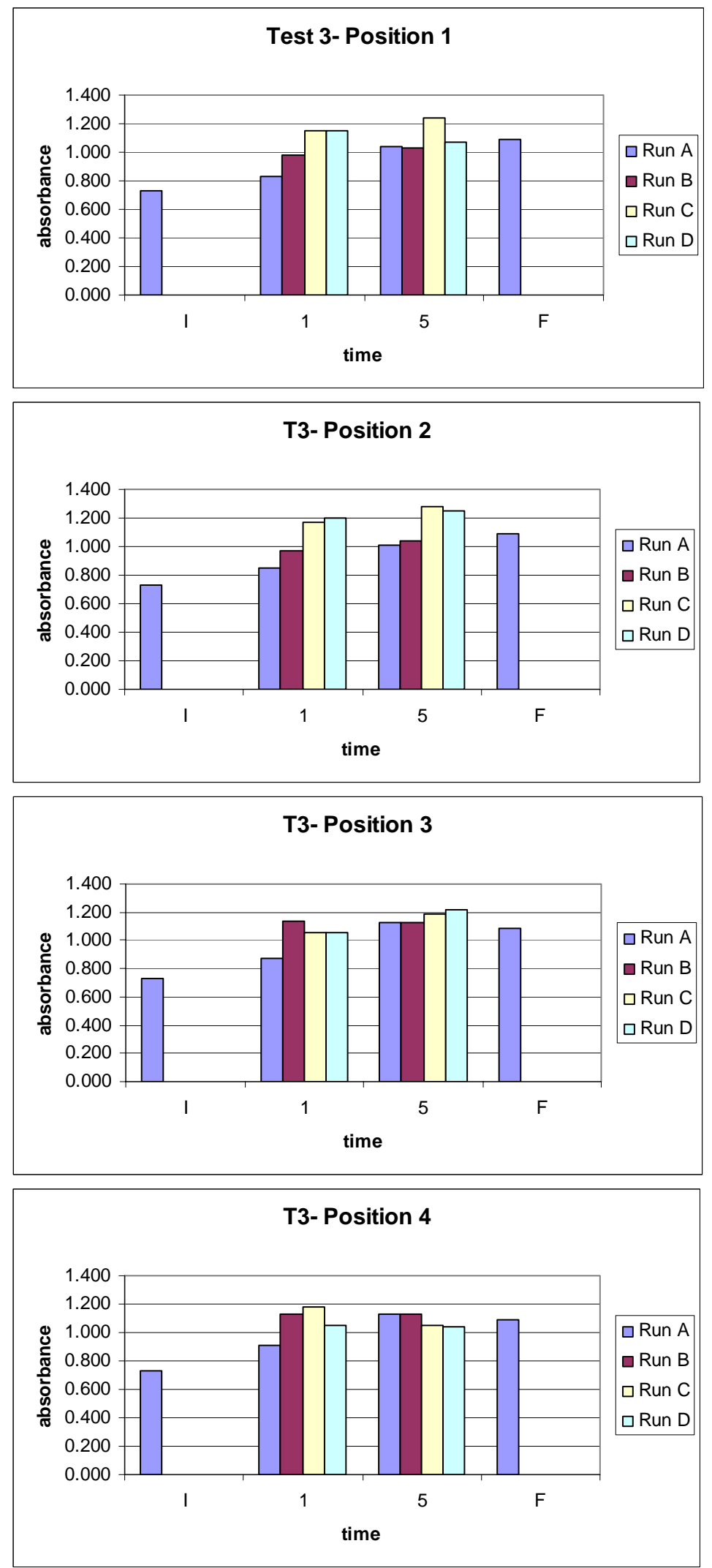

Figure 3. Test 3 
WSRC-TR-2004-00370, Rev. 0 July 12, 2004

Page 19 of 45

\begin{tabular}{|c|c|c|c|c|c|c|c|}
\hline Sample & Abs & Samp & Abs & Samp & Abs & Samp & Abs \\
\hline DI & 0.730 & & & & & & \\
\hline $1 \mathrm{~A} 1$ & 0.831 & 1B1 & 0.983 & $1 \mathrm{C} 1$ & 1.146 & 1D1 & 1.153 \\
\hline 1A5 & 1.042 & 1B5 & 1.035 & $1 \mathrm{C5}$ & 1.235 & 1D5 & 1.072 \\
\hline DF & 1.089 & & & & & & \\
\hline DI & 0.730 & & & & & & \\
\hline 2A1 & 0.854 & 2B1 & 0.974 & 2C1 & 1.166 & 2D1 & 1.198 \\
\hline 2A5 & 1.012 & 2B5 & 1.042 & $2 \mathrm{C5}$ & 1.276 & 2D5 & 1.255 \\
\hline DF & 1.089 & & & & & & \\
\hline DI & 0.730 & & & & & & \\
\hline 3A1 & 0.876 & 3B1 & 1.132 & $3 \mathrm{C} 1$ & 1.053 & 3D1 & 1.056 \\
\hline 3A5 & 1.122 & 3B5 & 1.129 & $3 C 5$ & 1.185 & 3D5 & 1.213 \\
\hline DF & 1.089 & & & & & & \\
\hline DI & 0.730 & & & & & & \\
\hline $4 \mathrm{~A} 1$ & 0.914 & 4B1 & 1.131 & $4 C 1$ & 1.176 & 4D1 & 1.053 \\
\hline 4A5 & 1.131 & 4B5 & 1.130 & $4 C 5$ & 1.055 & 4D5 & 1.043 \\
\hline DF & 1.089 & & & & & & \\
\hline
\end{tabular}

Table 3. Test 3 
WSRC-TR-2004-00370, Rev. 0

July 12, 2004

Page 20 of 45
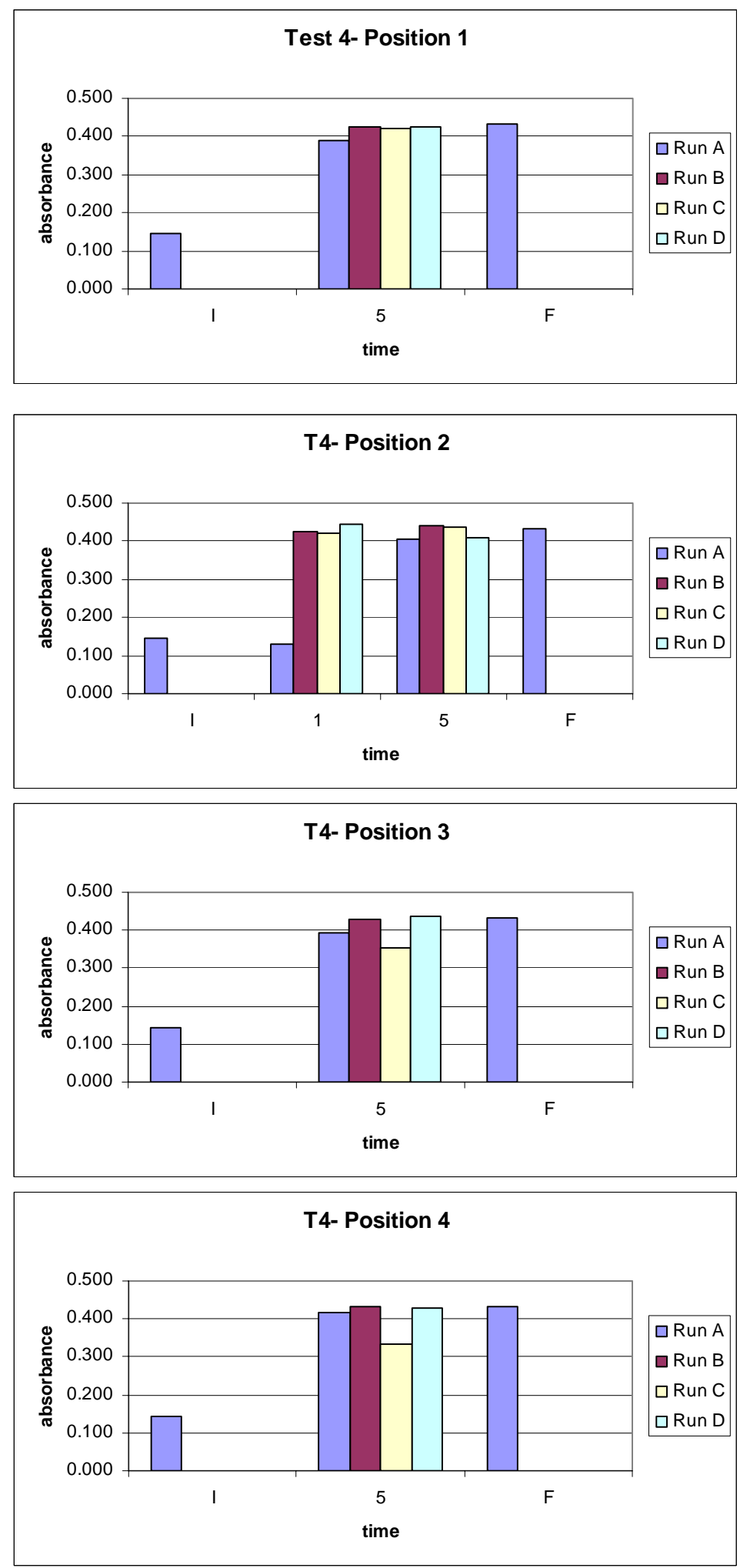

Figure 4. Test 4 
WSRC-TR-2004-00370, Rev. 0 July 12, 2004

Page 21 of 45

$\begin{array}{cccccccc}\begin{array}{c}\text { Test } 4 \\ \text { Sample } \\ \text { DI }\end{array} & \begin{array}{c}\text { Abs } \\ 0.145\end{array} & \text { Sample } & \text { Abs } & \text { Sample } & \text { Abs } & \text { Sample } & \text { Abs } \\ \text { 12A5 } & 0.391 & 12 \mathrm{~B} 5 & 0.424 & 12 \mathrm{C} 5 & 0.422 & 12 \mathrm{D} 5 & 0.426 \\ \text { DF } & 0.434 & & & & & & \\ & & & & & & & \\ \text { DI } & 0.145 & & & & & & \\ \text { 22A1 } & 0.13 & 22 \mathrm{~B} 1 & 0.427 & 22 \mathrm{C} 1 & 0.421 & 22 \mathrm{D} 1 & 0.445 \\ \text { 22A5 } & 0.405 & 22 \mathrm{~B} 5 & 0.440 & 22 \mathrm{C} 5 & 0.435 & 22 \mathrm{D} 5 & 0.410 \\ \text { DF } & 0.434 & & & & & & \\ & & & & & & & \\ \text { DI } & 0.145 & & & & & & \\ \text { 32A5 } & 0.392 & 32 \mathrm{~B} 5 & 0.430 & 32 \mathrm{C} 5 & 0.353 & 32 \mathrm{D} 5 & 0.436 \\ \text { DF } & 0.434 & & & & & & \\ \text { DI } & 0.145 & & & & & & \\ \text { 42A5 } & 0.417 & 42 \mathrm{~B} 5 & 0.431 & 42 \mathrm{C} 5 & 0.334 & 42 \mathrm{D} 5 & 0.428 \\ \text { DF } & 0.434 & & & & & & \end{array}$

Table 4. Test 4 
WSRC-TR-2004-00370, Rev. 0

July 12, 2004

Page 22 of 45
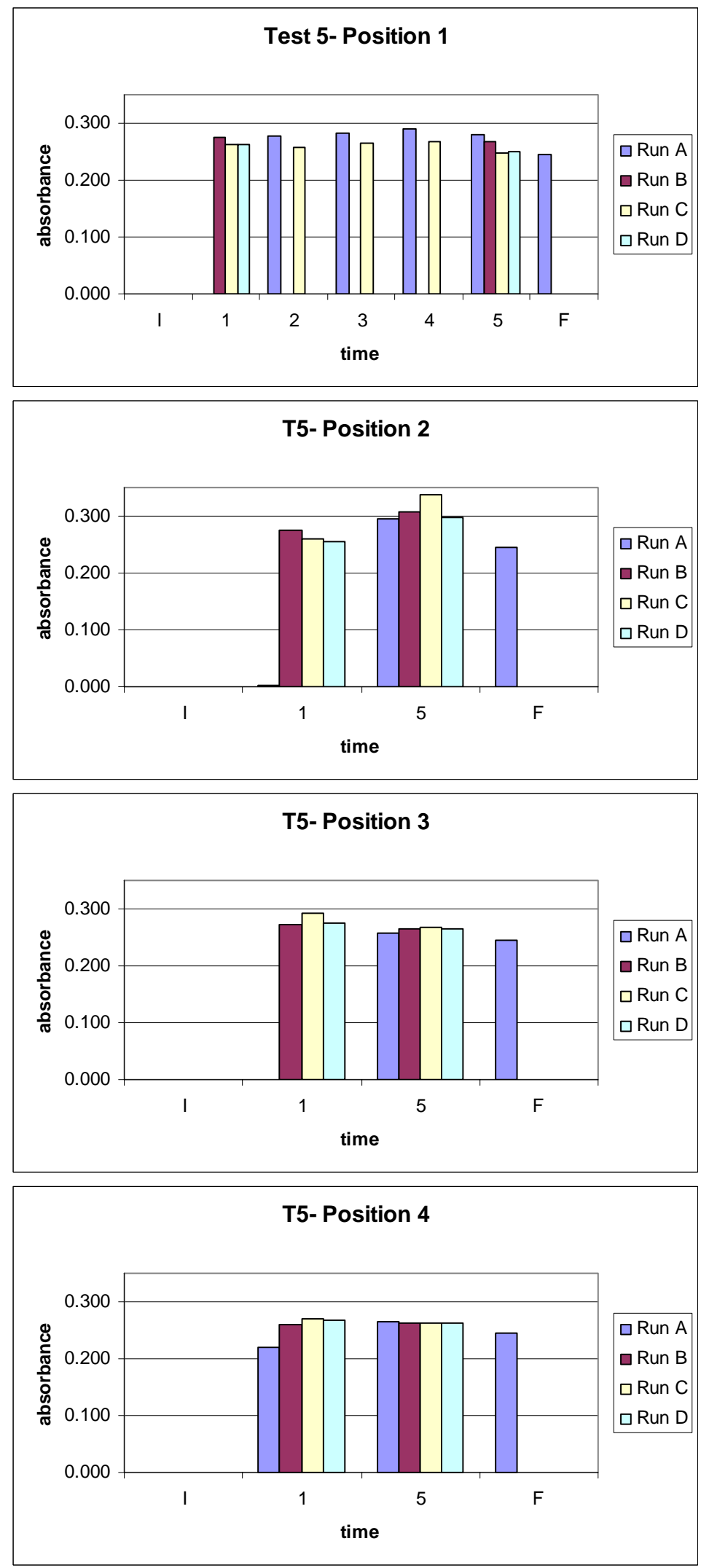

Figure 5. Test 5 
WSRC-TR-2004-00370, Rev. 0 July 12, 2004

Page 23 of 45

\begin{tabular}{|c|c|c|c|c|c|c|c|}
\hline $\begin{array}{c}\text { Sample } \\
\text { DI }\end{array}$ & $\begin{array}{c}\text { Abs } \\
0.001\end{array}$ & Sample & Abs & Sample & Abs & Sample & Abs \\
\hline $13 \mathrm{~A} 1$ & 0.001 & 13B1 & 0.274 & $13 \mathrm{C} 1$ & 0.262 & 1D1 & 0.263 \\
\hline $13 \mathrm{~A} 2$ & 0.279 & & & $13 C 2$ & 0.256 & & \\
\hline 13A3 & 0.282 & & & $13 C 3$ & 0.265 & & \\
\hline 13A4 & 0.291 & & & $13 C 4$ & 0.268 & & \\
\hline $13 A 5$ & 0.281 & $13 B 5$ & 0.268 & $13 C 5$ & 0.249 & 1D5 & 0.250 \\
\hline Fin & 0.244 & & & & & & \\
\hline DI & 0.001 & & & & & & \\
\hline 23A1 & 0.001 & 23B1 & 0.274 & $2 \mathrm{C} 1$ & 0.259 & 2D1 & 0.256 \\
\hline $23 A 5$ & 0.294 & 23B5 & 0.306 & $2 \mathrm{C} 5$ & 0.337 & 2D5 & 0.297 \\
\hline DF & 0.244 & & & & & & \\
\hline DI & 0.001 & & & & & & \\
\hline 33A1 & 0.001 & 33B1 & 0.272 & $3 \mathrm{C} 1$ & 0.292 & 3D1 & 0.274 \\
\hline 33A5 & 0.257 & 33B5 & 0.265 & $3 C 5$ & 0.267 & 3D5 & 0.265 \\
\hline DF & 0.244 & & & & & & \\
\hline DI & 0.001 & & & & & & \\
\hline 43A1 & 0.221 & 43B1 & 0.259 & $4 \mathrm{C} 1$ & 0.269 & 4D1 & 0.266 \\
\hline 43A5 & 0.265 & 43B5 & 0.263 & $4 C 5$ & 0.262 & 4D5 & 0.264 \\
\hline DF & 0.244 & & & & & & \\
\hline
\end{tabular}

Table 5. Test 5 
WSRC-TR-2004-00370, Rev. 0

July 12, 2004

Page 24 of 45
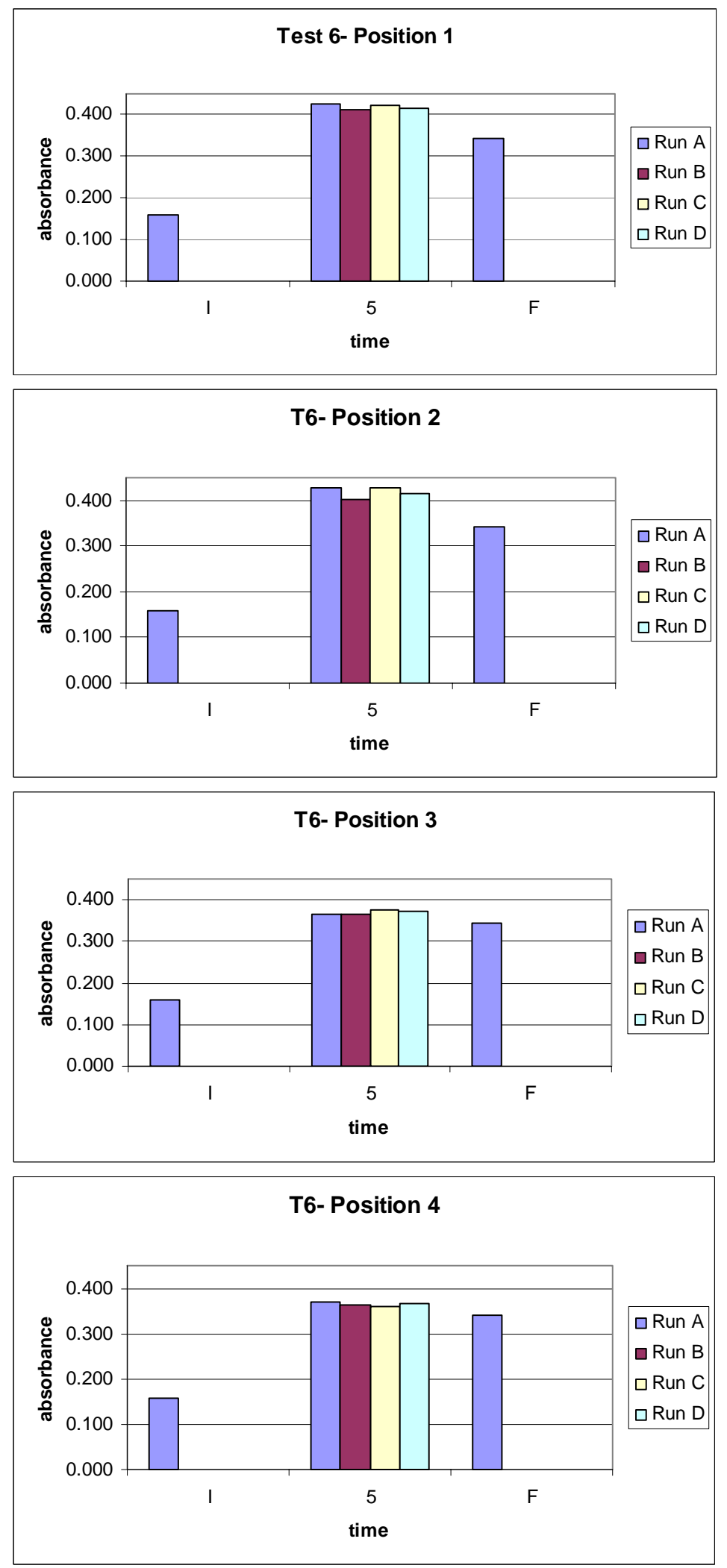

Figure 6. Test 6 
WSRC-TR-2004-00370, Rev. 0 July 12, 2004

Page 25 of 45

$\begin{array}{cccccccc}\begin{array}{c}\text { Test } 6 \\ \text { Sample }\end{array} & \text { Abs } & \text { Sample } & \text { Abs } & \text { Sample } & \text { Abs } & \text { Sample } & \text { Abs } \\ \text { DI } & 0.158 & & & & & & \\ \text { 14a5 } & 0.425 & 14 b 5 & 0.413 & 14 C 5 & 0.423 & 14 \mathrm{D} 5 & 0.414 \\ \text { DF } & 0.342 & & & & & & \\ \text { DI } & 0.158 & & & & & & \\ \text { 24a5 } & 0.427 & 24 b 5 & 0.403 & 24 C 5 & 0.427 & 24 \mathrm{D} 5 & 0.415 \\ \text { DF } & 0.342 & & & & & & \\ & & & & & & & \\ \text { DI } & 0.158 & & & & & & \\ 34 a 5 & 0.365 & 34 b 5 & 0.365 & 34 C 5 & 0.377 & 34 \mathrm{D} 5 & 0.372 \\ \text { DF } & 0.342 & & & & & & \\ \text { DI } & 0.158 & & & & & & \\ 44 a 5 & 0.369 & 44 b 5 & 0.363 & 44 C 5 & 0.361 & 44 D 5 & 0.367 \\ \text { DF } & 0.342 & & & & & & \end{array}$

Table 6. Test 6 
WSRC-TR-2004-00370, Rev. 0

July 12, 2004

Page 26 of 45
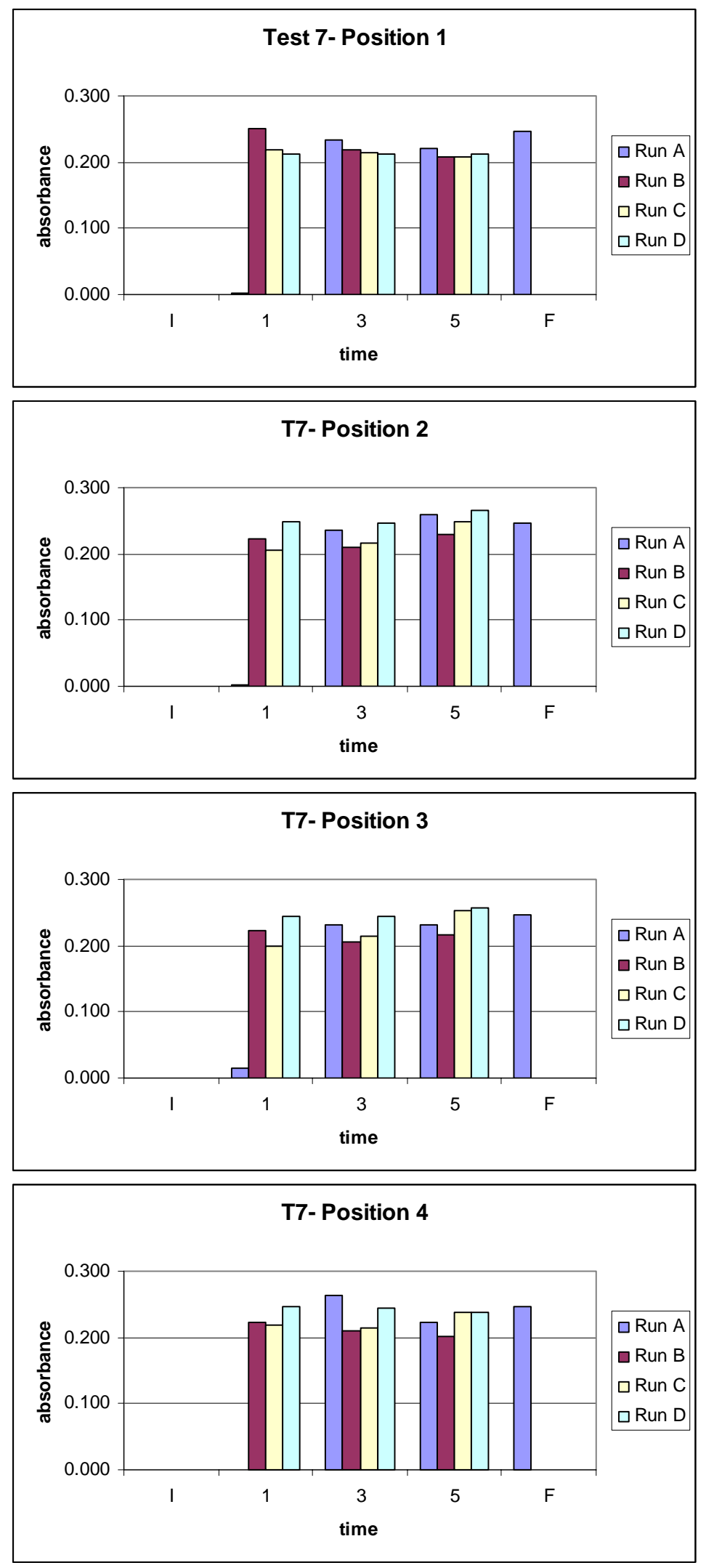

Figure 7. Test 7 
WSRC-TR-2004-00370, Rev. 0 July 12,2004

Page 27 of 45

\begin{tabular}{|c|c|c|c|c|c|c|c|}
\hline $\begin{array}{c}\text { Sample } \\
\text { DI }\end{array}$ & $\begin{array}{l}\text { Abs } \\
0.001\end{array}$ & Samp & Abs & Samp & Abs & Samp & Abs \\
\hline 17A1 & 0.002 & 17B1 & 0.250 & $17 \mathrm{C} 1$ & 0.218 & 17D1 & 0.211 \\
\hline 17A3 & 0.234 & 17B3 & 0.219 & $17 \mathrm{C} 3$ & 0.213 & 17D3 & 0.212 \\
\hline 17A5 & 0.221 & 17B5 & 0.208 & $17 \mathrm{C} 5$ & 0.207 & 17D5 & 0.212 \\
\hline DF & 0.245 & & & & & & \\
\hline DI & 0.001 & & & & & & \\
\hline 27A1 & 0.003 & 27B1 & 0.223 & $27 \mathrm{C} 1$ & 0.205 & 27D1 & 0.249 \\
\hline $27 \mathrm{~A} 3$ & 0.235 & 27B3 & 0.210 & $27 \mathrm{C} 3$ & 0.217 & 27D3 & 0.246 \\
\hline 27A5 & 0.260 & 27B5 & 0.229 & $27 \mathrm{C} 5$ & 0.249 & 27D5 & 0.266 \\
\hline DF & 0.245 & & & & & & \\
\hline DI & 0.001 & & & & & & \\
\hline $37 A 1$ & 0.015 & 37B1 & 0.224 & $37 \mathrm{C} 1$ & 0.200 & 37D1 & 0.243 \\
\hline $37 A 3$ & 0.231 & 37B3 & 0.206 & $37 \mathrm{C} 3$ & 0.214 & 37D3 & 0.244 \\
\hline $37 A 5$ & 0.232 & 37B5 & 0.216 & $37 \mathrm{C} 5$ & 0.254 & 37D5 & 0.256 \\
\hline DF & 0.245 & & & & & & \\
\hline DI & 0.001 & & & & & & \\
\hline 47A1 & 0.001 & 47B1 & 0.222 & $47 C 1$ & 0.219 & 47D1 & 0.247 \\
\hline $47 \mathrm{~A} 3$ & 0.263 & 47B3 & 0.210 & $47 \mathrm{C} 3$ & 0.214 & 47D3 & 0.244 \\
\hline $47 A 5$ & 0.222 & 47B5 & 0.201 & $47 C 5$ & 0.239 & 47D5 & 0.238 \\
\hline DF & 0.245 & & & & & & \\
\hline
\end{tabular}

Table 7. Test 7 
WSRC-TR-2004-00370, Rev. 0

July 12, 2004

Page 28 of 45
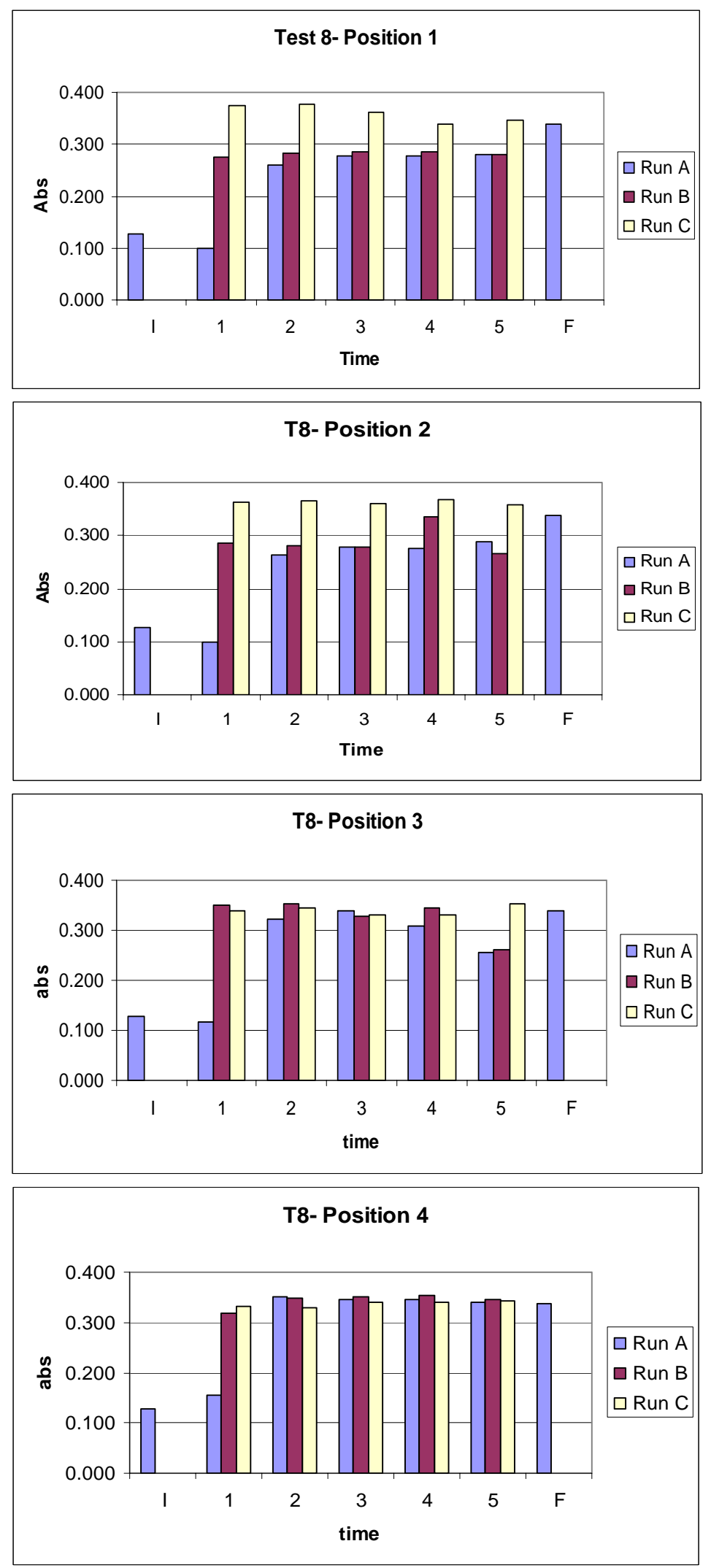

Figure 8. Test 8 
WSRC-TR-2004-00370, Rev. 0 July 12, 2004

Page 29 of 45

Test 8

Sample

$1 \quad 0.127$

18A1 0.099

18A2 0.259

18A3 0.279

18A4 0.278

18A5 0.282

FIN 0.338

$\begin{array}{ll}\text { I } & 0.127\end{array}$

28A1 0.100

28A2 0.264

28A3 0.278

28B1

0.285

$28 \mathrm{C} 1$

0.362

28B2

0.280

$28 \mathrm{C} 2$

0.366

28B3

0.277

$28 \mathrm{C} 3$

0.360

28A4 0.277

28B4

0.334

$28 \mathrm{C} 4$

0.367

28A5 0.287

28B5

0.266

$28 \mathrm{C} 5$

0.359

I $\quad 0.127$

38A1 0.116

38A2 0.323

38A3 0.338

38A4 0.309

38A5 0.256

FIN 0.338

38B1

0.351

$38 \mathrm{C} 1$

0.339

38B3

0.353

$38 \mathrm{C} 2$

0.344

38B4

0.328

$38 \mathrm{C} 3$

0.330

38B5

0.345

38C4 0.331

$0.262 \quad 38 C 5 \quad 0.353$

I $\quad 0.127$

48A1 0.156

48A2 $\quad 0.350$

48B1

0.319

$48 \mathrm{C} 1$

0.331

48A3 0.346

48B2

0.348

$48 \mathrm{C} 2$

0.330

48A4 0.345

48B3

0.352

$48 \mathrm{C} 3$

0.339

48A5 $\quad 0.340$

48B4

$48 \mathrm{C} 4 \quad 0.341$

FIN 0.338

48B5 0.346

48C5 $\quad 0.342$

Table 8. Test 8 
WSRC-TR-2004-00370, Rev. 0

July 12, 2004

Page 30 of 45
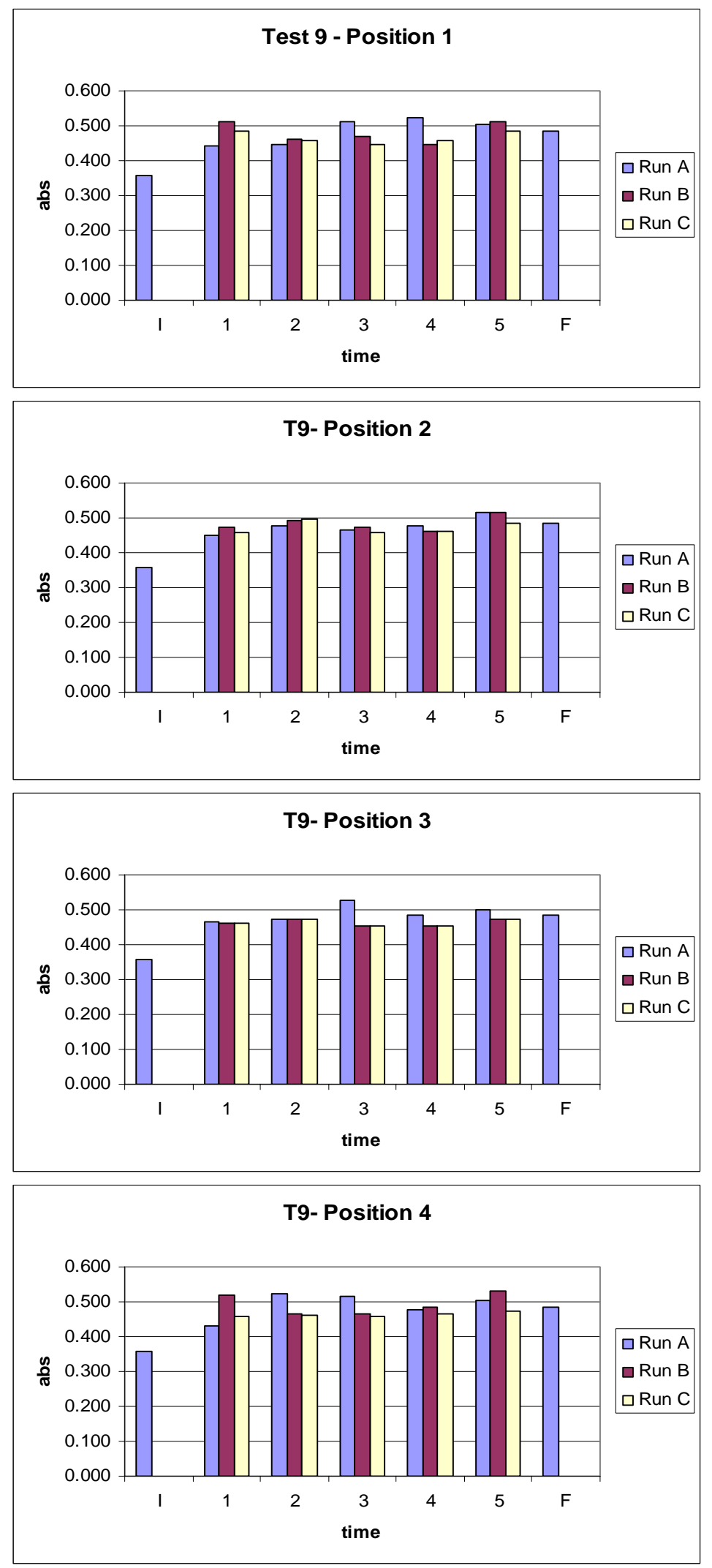

Figure 9. Test 9 
WSRC-TR-2004-00370, Rev. 0 July 12, 2004

Page 31 of 45

Test 9

Sample

Abs

$\begin{array}{cc}\text { Ini } & 0.359 \\ \text { 19A1 } & 0.444\end{array}$

Sample

Abs

Sample

Abs

19A2 0.445

19B1

0.512

$19 \mathrm{C} 1$

0.485

19B2

0.461

$19 \mathrm{C} 2$

0.458

19B3

0.468

$19 \mathrm{C} 3$

0.446

19A4 0.525

19B4

0.446

0.510

$19 \mathrm{C} 4$

0.459

19A5 0.505

19B5

$19 \mathrm{C} 5$

0.486

Ini $\quad 0.359$

29A1 0.452

29A2 0.477

29B1

0.471

29C1

0.456

29A3

0.467

29B2

0.493

$29 \mathrm{C} 2$

0.498

29A4

0.475

29B3

0.472

$29 \mathrm{C} 3$

0.458

29A5

29B4

0.462

$29 \mathrm{C} 4$

0.461

Fin $\quad 0.485$

29B5

0.516

$29 \mathrm{C} 5$

0.485

Ini $\quad 0.359$

39A1 0.464

39A2 0.472

39A3 0.526

39A4 0.485

39A5 0.499

Fin $\quad 0.485$

39B1

0.496

0.469

$39 \mathrm{~B} 3$

0.471

0.532

39B4

0.513

$39 \mathrm{C1}$

$39 \mathrm{C} 2$

39C3

39C4

$39 \mathrm{C} 5$

0.462

0.475

0.455

39B5

0.454

0.474

Ini $\quad 0.359$

49A1 $\quad 0.430$

49A2 $\quad 0.524$

49A3 $\quad 0.514$

49A4 $\quad 0.477$

49A5 0.504

Fin $\quad 0.485$

$\begin{array}{llll}\text { 49B1 } & 0.519 & 49 \mathrm{C} 1 & 0.456 \\ \text { 49B2 } & 0.465 & 49 \mathrm{C} 2 & 0.462 \\ \text { 49B3 } & 0.465 & 49 \mathrm{C} 3 & 0.457 \\ \text { 49B4 } & 0.486 & 49 \mathrm{C} 4 & 0.467 \\ \text { 49B5 } & 0.532 & 49 \mathrm{C} 5 & 0.473\end{array}$

Table 9. Test 9 
WSRC-TR-2004-00370, Rev. 0

July 12, 2004

Page 32 of 45
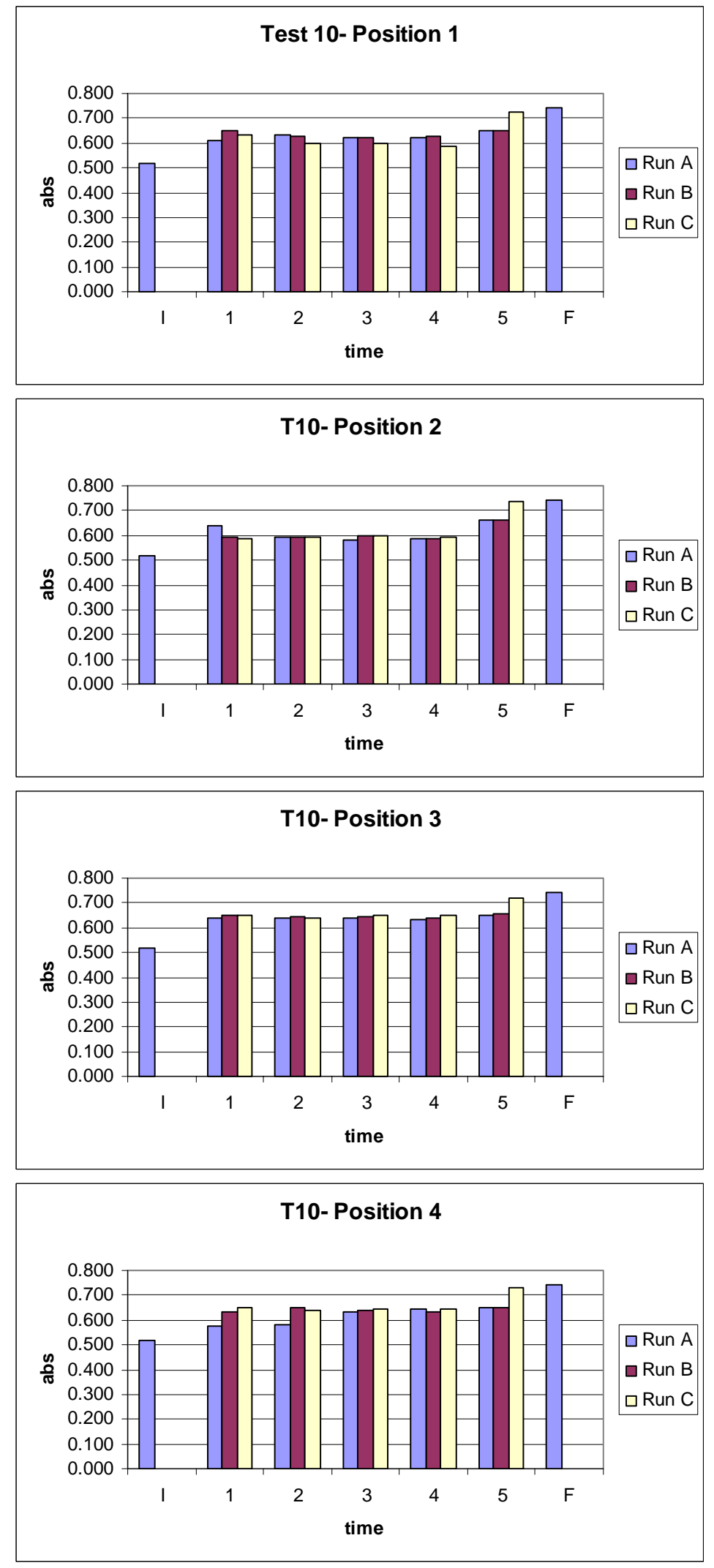

Figure 10. Test 10 
WSRC-TR-2004-00370, Rev. 0 July 12, 2004

Page 33 of 45

Test 10

Sample

Initial 0.520

110A1 0.608

$110 \mathrm{~A} 2 \quad 0.636$

$110 \mathrm{~A} 3 \quad 0.619$

$110 \mathrm{~A} 4 \quad 0.621$

$110 \mathrm{~A} 5 \quad 0.652$

final $\quad 0.740$

Initial $\quad 0.520$

210A1 0.638

210B

0.591

$210 \mathrm{C1}$

0.589

$210 \mathrm{~A} 2 \quad 0.593$

210B2

0.595

$210 \mathrm{C} 2$

0.592

210A3 0.584

210B3

0.596

$210 \mathrm{C} 3$

0.601

$210 \mathrm{~A} 4 \quad 0.585$

210B4 0.589

$210 \mathrm{C} 4$

0.592

210A5

210B5

0.659

$210 \mathrm{C} 5$

0.738

final $\quad 0.740$

Initial $\quad 0.520$

310A1 0.639

310A2 0.636

310B2 0.646

$310 \mathrm{C} 1 \quad 0.650$

310A3 0.639

310B3 0.642

$310 \mathrm{C} 2 \quad 0.641$

310C3 0.648

310A4 0.636

310B4 0.641

310C4 0.648

310A5 0.652

310B5 0.653

310C5 0.721

final $\quad 0.740$

Initial $\quad 0.520$

410A1 0.573

410B1 0.635

410C1 $\quad 0.649$

410A2 0.580

410B2 0.651

$410 \mathrm{C} 2 \quad 0.637$

$410 \mathrm{~A} 3 \quad 0.634$

410B3 0.636

$410 \mathrm{C} 3 \quad 0.647$

410A4 0.642

410B4 0.635

410C4 0.646

410A5 0.648

410B5 0.651

$410 \mathrm{C5} \quad 0.730$

Table 10. Test 10 
WSRC-TR-2004-00370, Rev. 0

July 12, 2004

Page 34 of 45
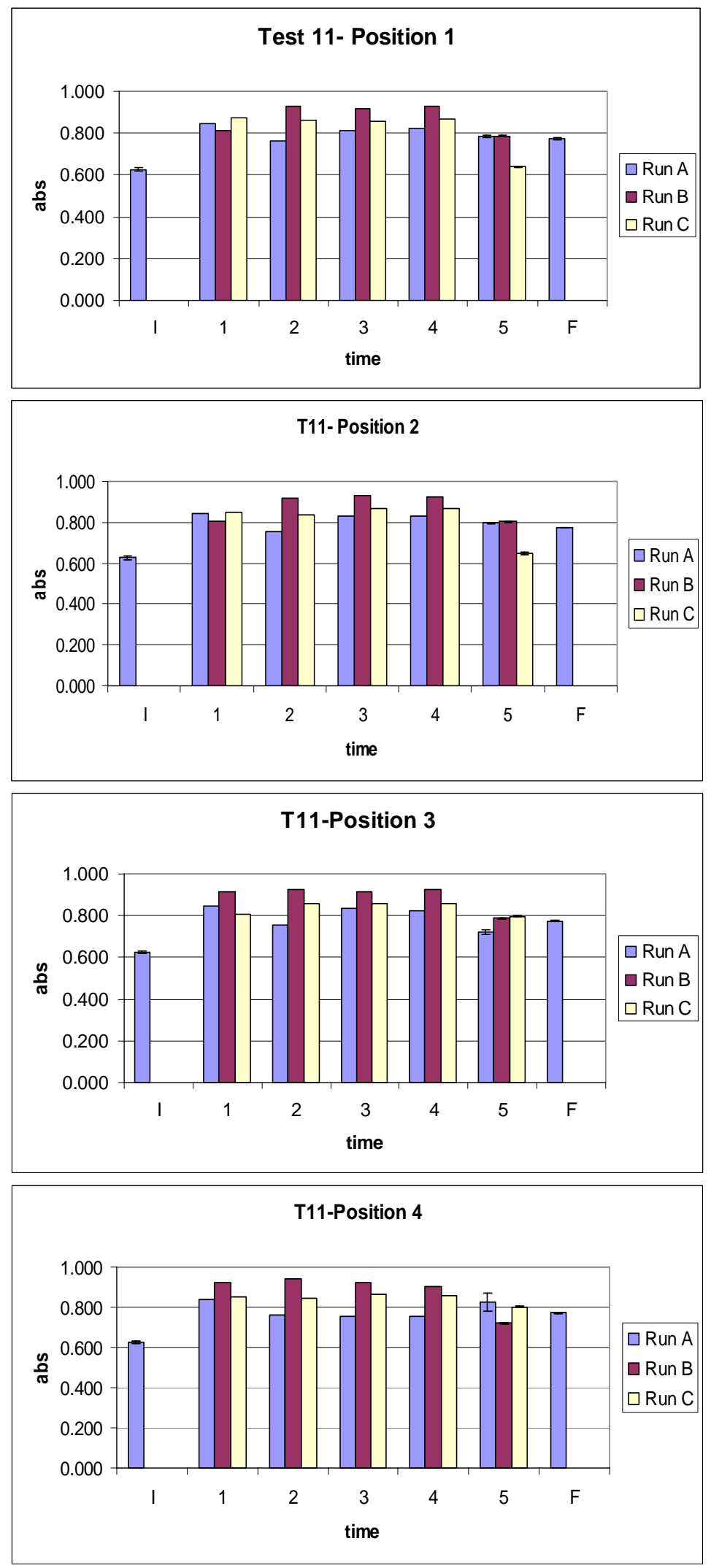

Figure 11. Test 11 
WSRC-TR-2004-00370, Rev. 0 July 12, 2004

Page 35 of 45

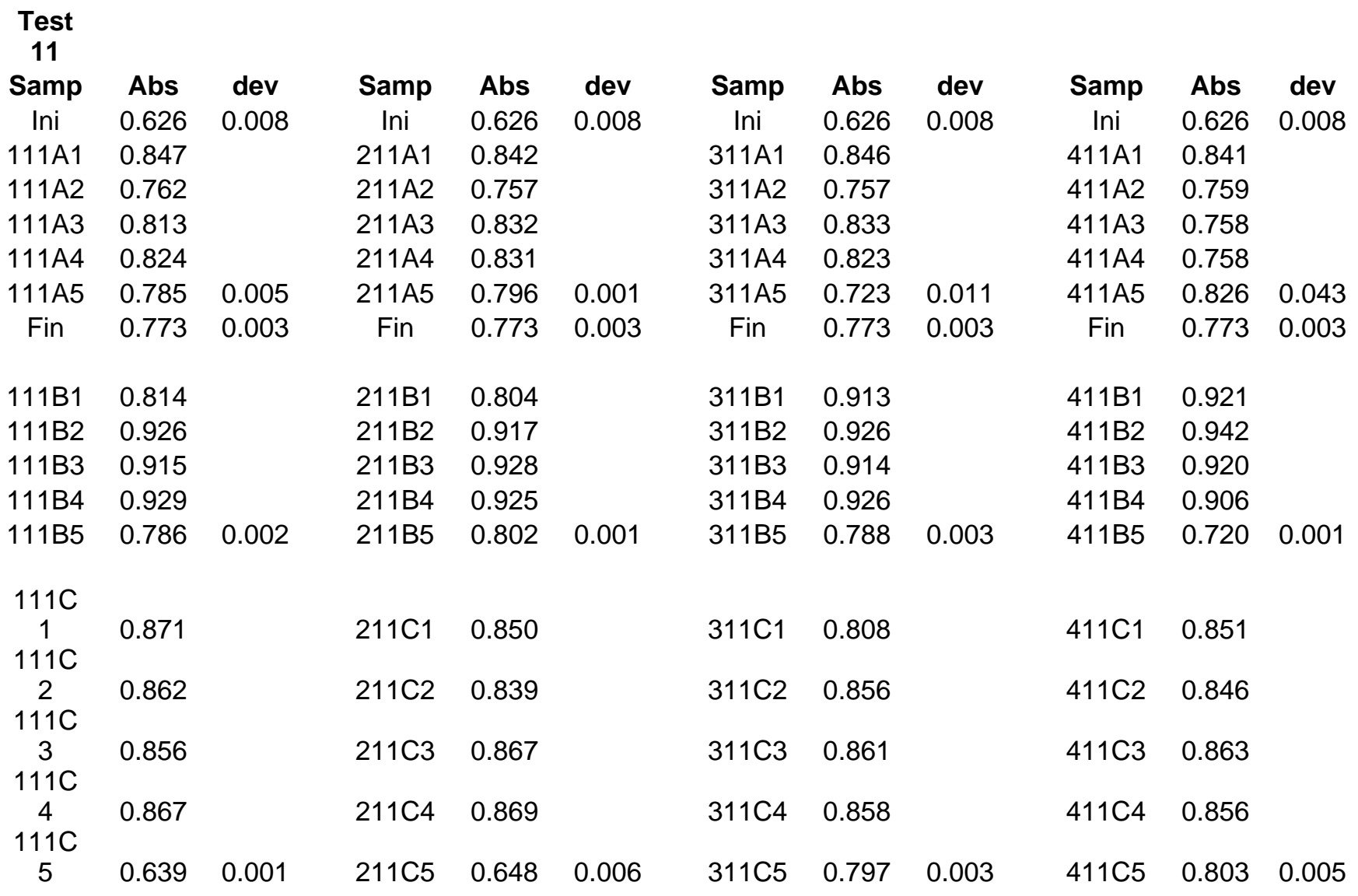

Table 11. Test 11 
WSRC-TR-2004-00370, Rev. 0

July 12, 2004

Page 36 of 45
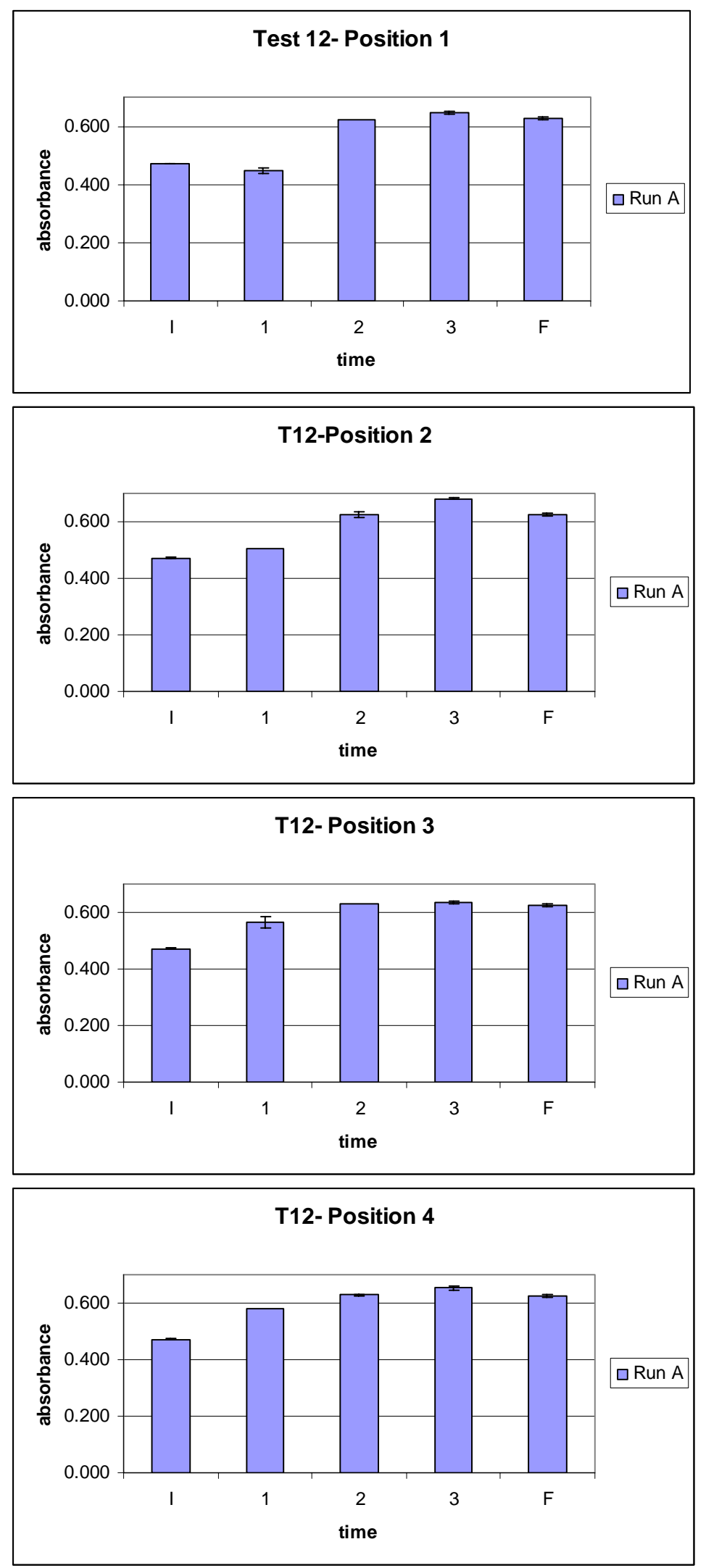
WSRC-TR-2004-00370, Rev. 0 July 12, 2004

Page 37 of 45

Figure 12. Test 12

\begin{tabular}{|c|c|c|}
\hline $\begin{array}{l}\text { Test } 12 \\
\text { Sample }\end{array}$ & Abs & dev \\
\hline I & 0.471 & 0.001 \\
\hline 1-12-A-1 & 0.447 & 0.008 \\
\hline $1-12-A-2$ & 0.620 & \\
\hline 1-12-A-3 & 0.646 & 0.003 \\
\hline Fin & 0.625 & 0.005 \\
\hline I & 0.471 & 0.001 \\
\hline $2-12-A-1$ & 0.507 & \\
\hline $2-12-A-2$ & 0.625 & 0.008 \\
\hline $2-12-A-3$ & 0.681 & 0.002 \\
\hline Fin & 0.625 & 0.005 \\
\hline I & 0.471 & 0.001 \\
\hline $3-12-A-1$ & 0.56 & 0.02 \\
\hline $3-12-A-2$ & 0.630 & \\
\hline $3-12-A-3$ & 0.636 & 0.004 \\
\hline Fin & 0.625 & 0.005 \\
\hline I & 0.471 & 0.001 \\
\hline $4-12-A-1$ & 0.580 & \\
\hline $4-12-A-2$ & 0.629 & 0.003 \\
\hline $4-12-A-3$ & 0.653 & 0.008 \\
\hline Fin & 0.625 & 0.005 \\
\hline
\end{tabular}

Table 12. Test 12 
WSRC-TR-2004-00370, Rev. 0

July 12, 2004

Page 38 of 45
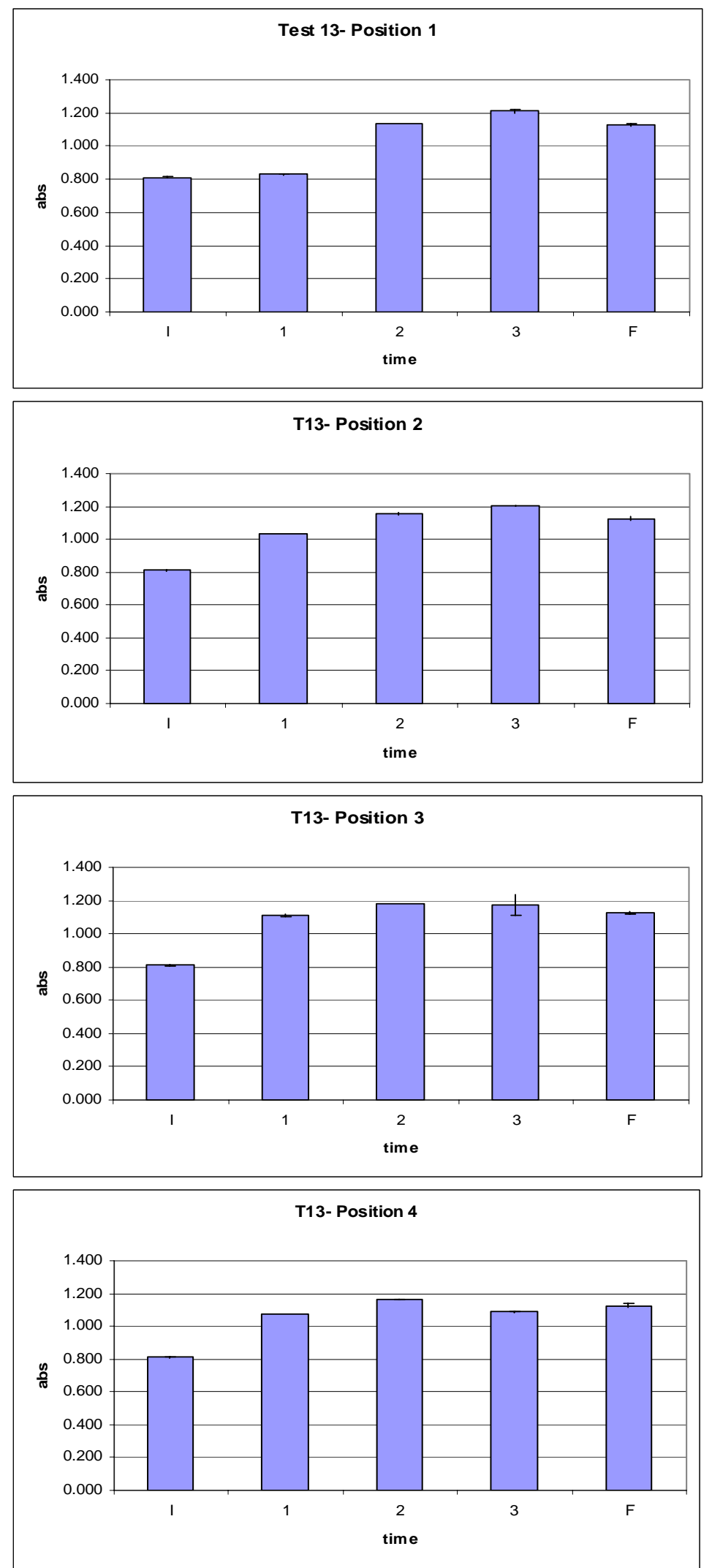

Figure 13. Test 13 
WSRC-TR-2004-00370, Rev. 0 July 12, 2004

Page 39 of 45

Test 13

Sample

Abs Dev

$0.810 \quad 0.004$

1-13-A1 $0.831 \quad 0.005$

1-13-A2 1.134

1-13-A3 $1.211 \quad 0.013$

Fin $\quad 1.126 \quad 0.010$

$\begin{array}{ccc}\text { I } & 0.810 & 0.004 \\ \text { 2-13-A1 } & 1.038 & \\ \text { 2-13-A2 } & 1.16 & 0.01 \\ \text { 2-13-A3 } & 1.204 & 0.001 \\ \text { Fin } & 1.126 & 0.010\end{array}$

$\begin{array}{ccc}\text { I } & 0.810 & 0.004 \\ \text { 3-13-A1 } & 1.111 & 0.007 \\ \text { 3-13-A2 } & 1.180 & \\ \text { 3-13-A3 } & 1.175 & 0.062 \\ \text { Fin } & 1.126 & 0.010\end{array}$

$\begin{array}{ccc}\text { I } & 0.810 & 0.004 \\ 4-13-A 1 & 1.077 & \\ \text { 4-13-A2 } & 1.164 & 0.002 \\ \text { 4-13-A3 } & 1.090 & 0.004 \\ \text { Fin } & 1.126 & 0.010\end{array}$

Table 13. Test 13 
WSRC-TR-2004-00370, Rev. 0

July 12, 2004

Page 40 of 45
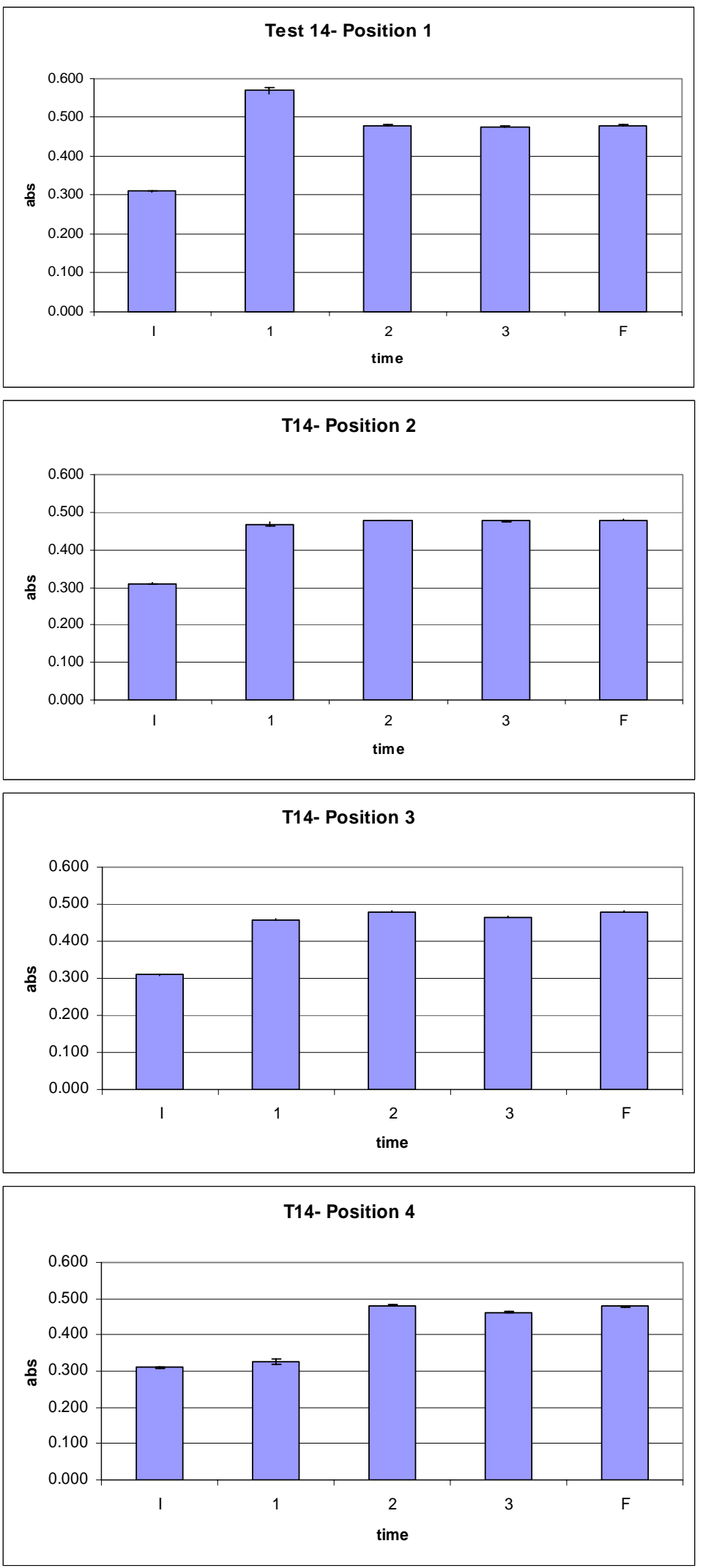

Figure 14. Test 14 
WSRC-TR-2004-00370, Rev. 0 July 12, 2004

Page 41 of 45

Test 14

Sample

Abs Dev

$0.310 \quad 0.001$

$\begin{array}{lll}1-13-A 1 & 0.569 & 0.008\end{array}$

1-13-A2 $0.480 \quad 0.001$

1-13-A3 $0.476 \quad 0.002$

Fin $\quad 0.480 \quad 0.002$

$\begin{array}{ccc}\text { I } & 0.310 & 0.001 \\ \text { 2-13-A1 } & 0.468 & 0.006\end{array}$

2-13-A2 $\quad 0.477 \quad 0.000$

2-13-A3 $0.476 \quad 0.002$

Fin $\quad 0.480 \quad 0.002$

$\begin{array}{ccc}\text { I } & 0.310 & 0.001 \\ \text { 3-13-A1 } & 0.459 & 0.001 \\ \text { 3-13-A2 } & 0.480 & 0.002 \\ \text { 3-13-A3 } & 0.465 & 0.002 \\ \text { Fin } & 0.480 & 0.002\end{array}$

$\begin{array}{lll}\text { I } & 0.310 & 0.001\end{array}$

$\begin{array}{lll}4-13-\mathrm{A} 1 & 0.327 & 0.007\end{array}$

4-13-A2 $0.481 \quad 0.002$

4-13-A3 $0.462 \quad 0.002$

Fin $\quad 0.480 \quad 0.002$

Table 14. Test 14 
WSRC-TR-2004-00370, Rev. 0

July 12, 2004

Page 42 of 45
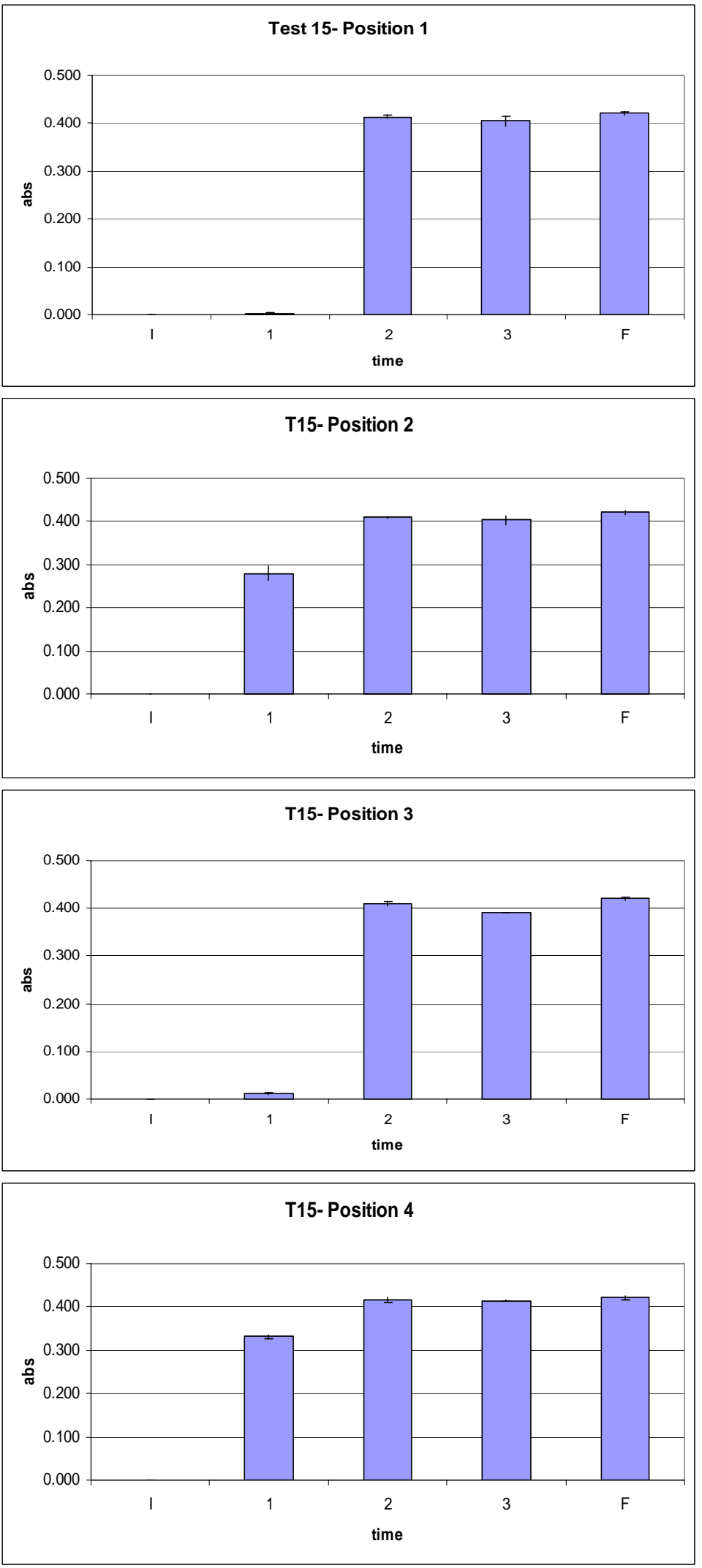

Figure 15. Test 15 
WSRC-TR-2004-00370, Rev. 0 July 12,2004

Page 43 of 45

Test 15

Sample

Abs Dev

Ini $\quad 0.0006 \quad 0.0002$

$\begin{array}{lll}1-15 A-1 & 0.0032 & 0.0004\end{array}$

$1-15 A-2 \quad 0.413 \quad 0.003$

1-15A-3 $0.40 \quad 0.01$

Fin $\quad 0.421 \quad 0.004$

Ini $\quad 0.0006 \quad 0.0002$

2-15A-1 $\quad 0.28 \quad 0.02$

2-15A-2 $\quad 0.410 \quad 0.001$

2-15A-3 $0.40 \quad 0.01$

$\begin{array}{lll}\text { Fin } & 0.421 & 0.004\end{array}$

$\begin{array}{lll}\text { Ini } & 0.0006 & 0.0002\end{array}$

3-15A-1 $0.012 \quad 0.002$

3-15A-2 $0.409 \quad 0.005$

3-15A-3 $0.391 \quad 0.001$

Fin $\quad 0.421 \quad 0.004$

$\begin{array}{lll}\text { Ini } & 0.0006 \quad 0.0002\end{array}$

$\begin{array}{lll}4-15 A-1 & 0.331 & 0.005\end{array}$

4-15A-2 $\quad 0.416 \quad 0.007$

4-15A-3 $\quad 0.414 \quad 0.001$

Fin $\quad 0.421 \quad 0.004$

Table 15. Test 15 
WSRC-TR-2004-00370, Rev. 0

July 12, 2004

Page 44 of 45
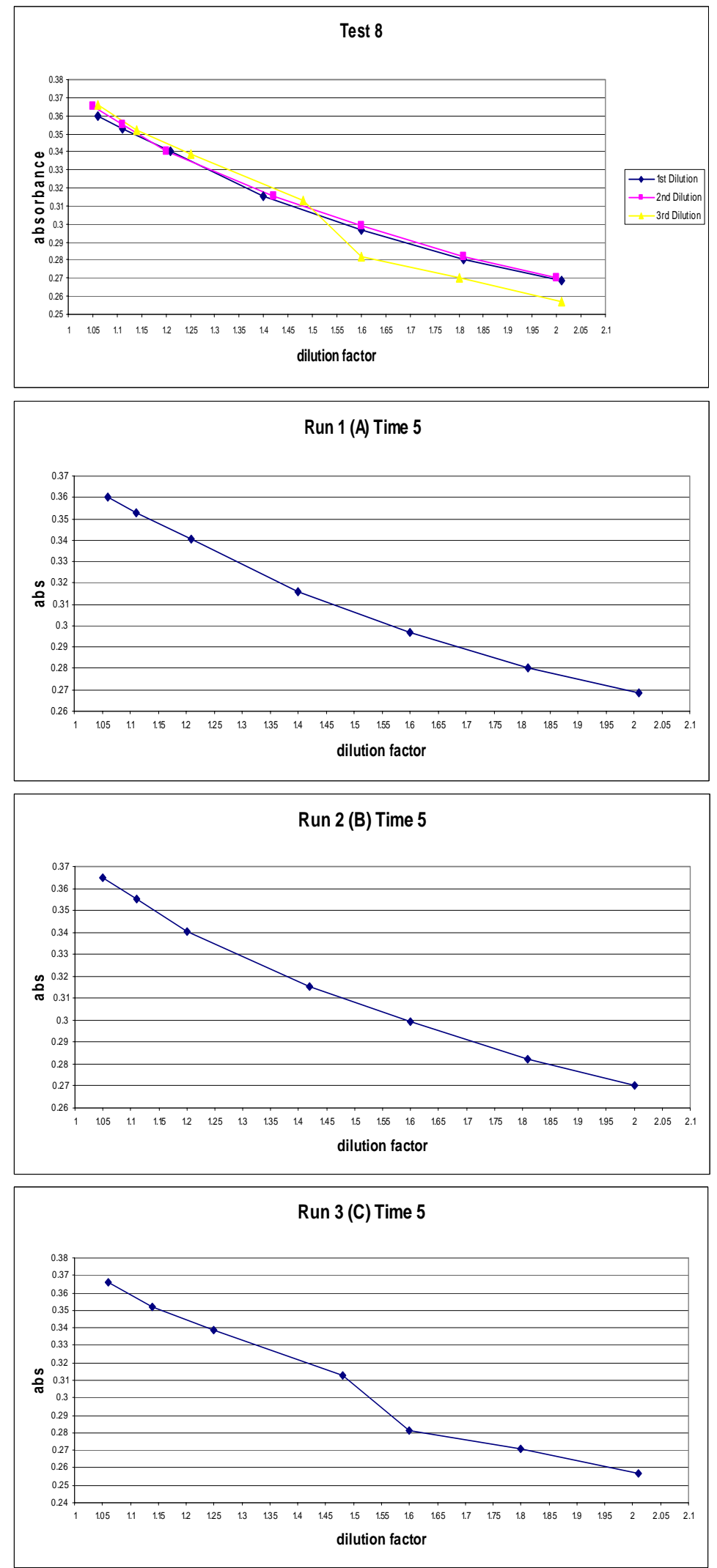

Appendix 1. Dilution curves and mixed percent calculation 
WSRC-TR-2004-00370, Rev. 0 July 12, 2004

Page 45 of 45

$\begin{array}{lclc}\text { Position 1 } & \text { Abs } & & \text { dil fac } \\ \text { sample from run cond 2 (18B5) } & 0.279 & \text { plot on diluted 1st set } & 1.83 \\ \text { sample from run cond 3 (18C5) } & 0.345 & \text { plot on diluted 2nd set } & 1.17 \\ \text { DF } & 0.338 & & 1.25\end{array}$

Run $3 \quad 1.25 \quad 1.25=100 \% /$ R3\% $\quad 80 \quad \%$ mixed

Run $2 \quad 1.17 \quad 1.17=80 \% /$ R2\% $\quad 68 \quad \%$ mixed

Run $1 \quad 1.83 \quad 1.83=68 \% / \mathrm{R} 1 \% \quad 37 \quad \%$ mixed

\begin{tabular}{|c|c|c|c|c|c|}
\hline \multirow{3}{*}{\multicolumn{3}{|c|}{$\begin{array}{l}\text { Position } 2 \\
\text { sample from run cond } 2 \text { (28B5) } \\
\text { sample from run cond } 3 \text { (28C5) }\end{array}$}} & \multirow{2}{*}{$\begin{array}{c}\text { Abs } \\
0.278\end{array}$} & \multirow{2}{*}{\multicolumn{2}{|c|}{ plot on dilute }} \\
\hline & & & & & \\
\hline & & & 0.351 & & \\
\hline & & DF & 0.338 & & \\
\hline 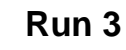 & 1.25 & $1.25=100 \% /$ & & 80 & \\
\hline Rur & 1.15 & $1.15=80 \% / \mathrm{R} 2$ & & 70 & \\
\hline Run 1 & 1.85 & $1.85=70 \% / \mathrm{R} 1$ & & 56 & $\%$ \\
\hline
\end{tabular}

$\begin{array}{lclc}\text { Position 3 } & \text { Abs } & & \text { dil fac } \\ \text { sample from run cond 2 (38B5) } & 0.257 & \text { plot on diluted 1st set } & 2.3 \\ \text { sample from run cond 3 (38C5) } & 0.348 & \text { plot on diluted 2nd set } & 1.16 \\ \text { DF } & 0.338 & & 1.25\end{array}$

$\begin{array}{lclll}\text { Run 3 } & 1.25 & 1.25=100 \% / \mathrm{R} 3 \% & \mathbf{8 0} & \% \text { mixed } \\ \text { Run 2 } & 1.16 & 1.16=80 \% / \mathrm{R} 2 \% & \mathbf{6 9} & \% \text { mixed } \\ \text { Run 1 } & 2.3 & 2.3=69 \% / \mathrm{R} 1 \% & \mathbf{3 0} & \% \text { mixed }\end{array}$

$\begin{array}{lclc}\text { Position 4 } & \text { Abs } & & \text { dil fac } \\ \text { sample from run cond 2 (48B5) } & 0.343 & \text { plot on diluted 1st set } & 1.19 \\ \text { sample from run cond 3 (48C5) } & 0.338 & \text { plot on diluted 2nd set } & 1.23 \\ \text { DF } & 0.338 & & 1.25\end{array}$

$\begin{array}{lllll}\text { Run 3 } & 1.25 & 1.25=100 \% / \mathrm{R} 3 \% & \mathbf{8 0} & \% \text { mixed } \\ \text { Run 2 } & 1.23 & 1.23=80 \% / \mathrm{R} 2 \% & \mathbf{6 5} & \% \text { mixed } \\ \text { Run 1 } & 1.19 & 1.19=65 \% / \mathrm{R} 1 \% & \mathbf{5 5} & \% \text { mixed }\end{array}$

Appendix 1. (cont.) Dilution curves and mixed percent calculation 